Document downloaded from:

http://hdl.handle.net/10251/106297

This paper must be cited as:

De-Miguel-Molina, B.; Cunningham, SW.; Palop Marro, FR. (2017). Analyzing Funding Patterns and Their Evolution in Two Medical Research Topics. International Journal of Innovation and Technology Management (Online). 14(2):1-39.

doi:10.1142/S0219877017400107

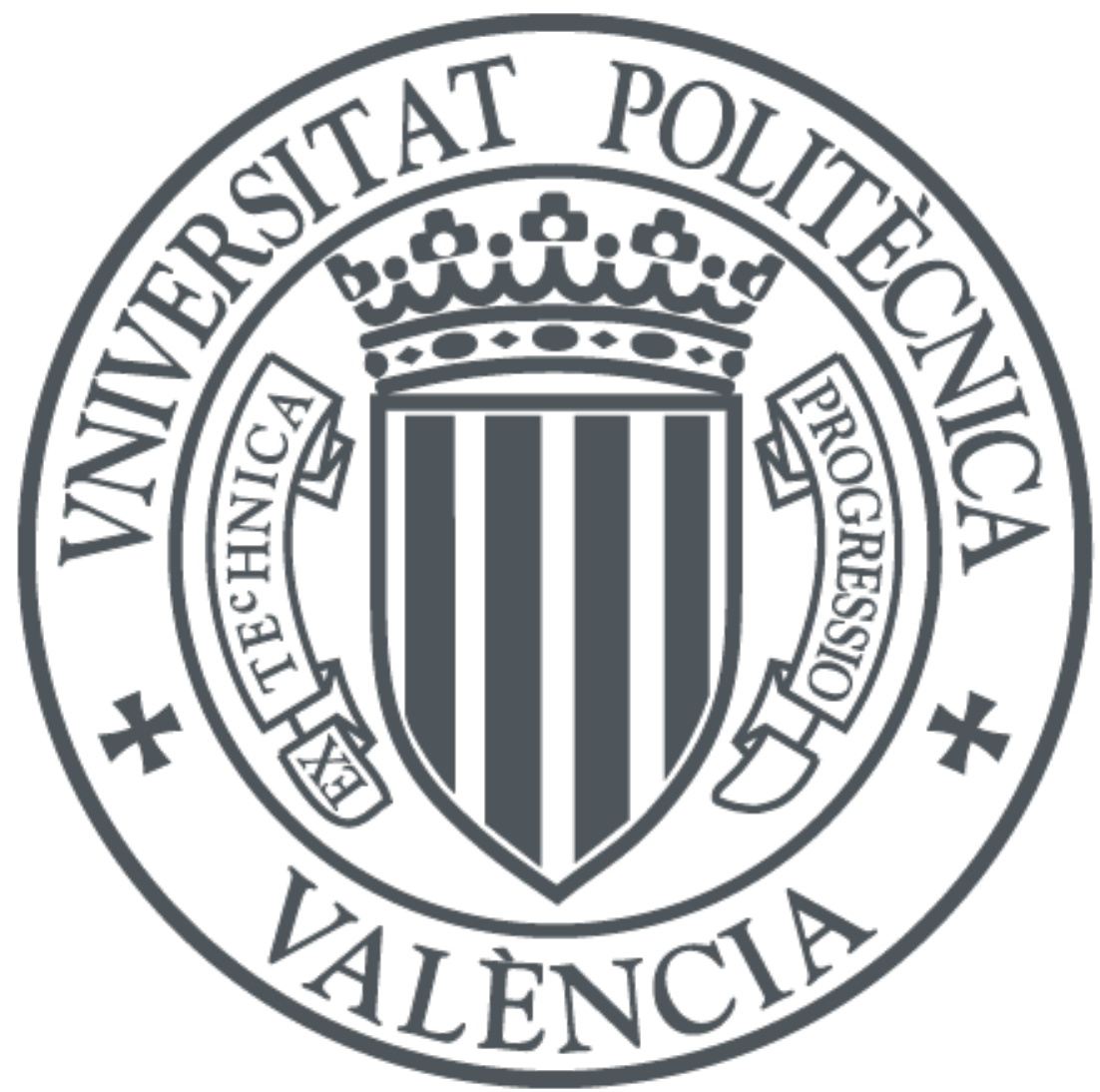

The final publication is available at

https://doi.org/10.1142/S0219877017400107

Copyright World Scientific

Additional Information 
Authors' pre-refereeing version,

Available at: https://www.worldscientific.com/doi/abs/10.1142/S0219877017400107

This paper must be cited as:

Blanca De-Miguel-Molina, Scott W. Cunningham, and Fernando Palop (2017). Analysing funding patterns and their evolution in two medical research topics. International Journal of Innovation and Technology Management, 14, 1740010 [39 pages] https://doi.org/10.1142/S0219877017400107

\title{
ANALYSING FUNDING PATTERNS AND THEIR EVOLUTION IN TWO MEDICAL RESEARCH TOPICS
}

\author{
Blanca De-Miguel-Molina ${ }^{1, *}$, Scott W. Cunningham ${ }^{2}$, Fernando Palop ${ }^{1}$ \\ ${ }^{1}$ Management Department, Universitat Politècnica de València, Camino de Vera s/n, Building 7D, \\ Valencia 46022, Spain \\ ${ }^{2}$ Multi-Actor Systems Department, TU Delft, Jaffalaan 5, Delft, 2628 BX Delft, The Netherlands \\ *Corresponding author.
}

\begin{abstract}
This paper analyses funding patterns and their evolution in two medical research topics: breast cancer and ovarian cancer, taking into account cross-agency and cross-national co-funding. A bibliometric analysis of 355,463 papers from PubMed $(273,526$ on breast cancer and 81,937 on ovarian cancer) brought back 91 funding agencies involved in breast cancer and 65 in ovarian cancer. Additionally, the article examined the evolution of Medical Subject Headings (MESH) funded by agencies. An analysis of patterns in funding, co-funding, MESH, and their evolution, was carried out using Social Network Analysis (SNA) methodology. The results show the importance of the National Cancer Institute (NCI) in both breast and ovarian cancer. The NCI achieves its policy goals by co-funding its programmes with both national and cross-national agencies. Moreover, the MESH that agencies co-funded in the two years studied coincided; however, it must be said that the number of agencies which participated in research funding also increased.
\end{abstract}

Keywords: co-funding research; Medical Subject Headings (MESH); cancer research; social network analysis.

\section{Introduction}

There are a number of open questions to be analysed regarding the role of funding agencies in the production of scientific activity. The first question concerns the role of research funding agencies in the selection and prioritisation of research topics deserving further funding. The second question concerns how funding agencies accomplish their policy objectives in tandem with other research funders. Although separate funding agencies wish to work together, obstacles occur as a result of agency preferences, national and organisational boundaries, and the nature of the funding instruments used. A third question therefore centres on the obstacles encountered by research funding agencies when funding scientific research, given the different cultures, objectives, and instruments found in cross-funding recipients.

This paper helps to address some of these questions by using funding acknowledgements from a national medical funding database. Although there is a growing availability of this data, there is still a relative lack of empirical papers which utilise this information [Vanderelst and Speybroeck (2013); Zhou and Tian (2014); Tahmooresnejad et al. (2014)]. Yet, thanks to this data we are able to investigate a number of questions, including the co-funding patterns of research agencies, and how funding differs according to topics and domains. Finally, this novel source of information enables us to dig deeper into the role of capstone funding agencies in creating a larger ecology of funders and principal investigators. 
We investigated these questions and this data using two medical research topics selected from the PubMed database. The paper is organised as follows. Section 2 provides a short literature review of some of the key questions underlying the production of scientific knowledge through research funding and funding agencies. Section 3 provides a methodological review of specific methods used to investigate these questions. Section 4 details the data, and its cleaning and extraction. Section 5 shows the results of social network analysis and co-word analysis of the database. The paper concludes in section 6 with recommendations and topics for future research.

\section{Literature Review}

The processes of selecting, prioritising and funding specific areas in science are complex and varied. There are no palimpsests to be read which describe the key issues to be addressed through science, or the needs of society which might be met through scientific funding. Any effort to select topics for further funding must meet a balance of external and internal criteria [Weinberg (1963)]. External criteria include the perceived need and value of research in society. Internal criteria involve maintaining a pipeline of viable research, as well as a stable of scientific talent across the entirety of the life cycle.

Access to funding is a matter of governance, addressed like many other societal questions from the viewpoint of the use of scarce resources [Cunningham (2007)]. Direct societal and citizen input into scientific funding occurs through science advisory councils [Brickman and Rip (1979)]. Nonetheless, even this mechanism has changed over time given the general availability of funding and changing public attitudes towards public funding for science and technology. The military is a common sponsor of science in a broad range of disciplines. The specific purpose of military funding is to develop weapons, or further foreign policy objectives [Doel (2003)]. The extent to which science is funded by the state as a public good is part of a larger political agenda waged between larger, self-sufficient corporations and smaller firms with limited resources [Lassman (2005)]. A new economics of science questions the allocative efficiency of funding agencies as a means towards providing a broader, conceptual framework for analysing science and its funding [Dasgupta and David (1994)].

Science is increasingly a polycentric activity, funded by a variety of different actors for a variety of different purposes. In the developed world, national governments and their respective agencies are not necessarily the dominant source for funding science and technology. This has arisen as a result of a decline in national funding in the wake of the Cold War, as well as an increase in private-sector funding. The consequence of this is that public science is produced from an amalgam of different sources, providing funding with different purposes, different terms, and differing conditions.

Transdisciplinary research thrives in the boundaries between different organisations, as well as in the formulation and translation of research to meet the varied needs of society [Nowotny et al. (2003)]. Despite the opportunities that are created by new modes of knowledge production, care is still needed in selecting from a diverse portfolio of potential research topics [Stirling (2007)]. Explicit attention is necessary in enhancing overall participation and deliberation concerning the selection of research. An amalgamation of funding can lead to a lack of inter-agency coordination, and certainly introduces new modes of potential system failure [Negro et al. (2012]. Overweening failure, to which even centralised agencies are subject, is a premature lock-in into undesirable or inefficient forms of technology [Cowan (1991)]. This problem is exacerbated when research funding is scarce, and scientific choice is thereby restricted.

Funding agencies face obstacles in the selection of research projects. These obstacles emerge out of hard and soft institutional rules. Epistemic boundaries on funding occur given the specific objectives of the funding agency, which may limit the kinds of science it is funding. There are also agency problems - the agency may find it difficult to effectively evaluate certain kinds of knowledge with which it is not familiar. National or geographical limits on funding can also occur given the specific mission of the 
agency. Other obstacles occur because of differing incentives between the funding agency and the respective scientific organisations which receive funding. These kinds of obstacles exist between funding agencies and funded organisations, but they also manifest themselves as challenges on which funding agencies need to work together towards common interests.

The issue of funding obstacles has been addressed in part by the Dutch school of geography, which addresses and generalises the concept of proximity. Proximity entails geographical factors, but also includes epistemic and institutional factors as well [Cunningham and Werker (2012)]. These funding obstacles are partly considered within extensive literature on technology transfer. Literature highlights the many contingent factors under which funding is successful, and technological knowledge is then transferred [Bozeman (2000)]. Nonetheless, and despite these hurdles, the importance of publically funded science for the production of new technology is well documented [Narin et al. (1997)].

Despite renewed calls to set forth an agenda for research into scientific policy [Sutherland et al. (2012)], the three questions set forth here have received relatively little coherent attention in literature. There is an even greater gap when it comes to systematic and empirical evidence for how scientific networks are shaped by their funding. An exception is Lewison (1998) whose investigations centred on the diversity of research funding associated with research teams in medical research. Given this gap in the literature, an exploratory and empirical analysis of how epistemic networks are shaped by funding agencies, and how funding agencies find (or fail to find) common cause with other agencies, is of empirical and theoretical interest.

\section{Methodology}

Bibliometric and scientometric analysis are common in the representation of science maps in literature reviews, including medical literature reviews [Zhang et al. (2013); Ramlogan and Consoli (2014)]. Measures like co-authorship and co-word analyses are frequently used to analyse data. Moreover, the Social Network Analysis (SNA) methodology is also used to find out who the main research actors are, whether people, institutions, or countries. The technique is also used to reveal cooperation between actors, and keyword co-occurrence. This constellation of metrics is very helpful in understanding how knowledge evolves in a specific field.

The measures from Social Network Analysis usually employed in literature reviews are centrality, including degree centrality, closeness and betweenness. Moreover, statistical analyses, such as cluster detection and multidimensional scaling, are also applied to group together words, authors, and institutions. Degree centrality, in the case of variables organised in 1-mode matrix, represents the most important nodes in the network, that is, nodes that have the largest number of connections (links) with other nodes. Closeness defines the average distance between one node and other nodes [Borgatti et al. (2013)], and betweenness indicates whether a node is frequently located on paths between other nodes [Kolaczyk (2009)]. An additional measure for networks, which is useful in a dense network, is clique detection. A clique is a sub-network with three nodes or more [de Nooy et al. (2012] in which all actors are directly connected to all others [Hanneman and Riddle (2011)].

Bibliometric and scientometric analyses and SNA are often complemented with the visualisation of networks, a tool which helps to reveal key information about the network [Ozcan and Islam (2013); Feng et al. (2015)]. Tools for visualising networks have been developed over the last few years, both in commercial and free formats [van Eck and Waltman (2010); Cobo et al. (2011); Light et al. (2014)]. These tools, like VOSViewer [van Eck and Waltman (2010)] and Gephi [Bastian et al. (2009)], also allow researchers to apply measures and models to analyse nodes and links, including centrality measures and clustering.

Collaborative network analysis has been employed to study relationships between authors and organisations in many different disciplines [Kumar and Jan (2013); Qiu et al. (2014)]. In the case of 
health, there are studies in which data about collaboration comes from academic papers [Catalá-López et al. (2014); Andersen et al. (2015)], whilst in other studies these come from website inter-linkages [Barreto Lang et al. (2013)].

Co-words and co-keyword analysis are also measures used in papers where bibliometric and scientometric analyses are applied as the main methodology [Neff and Corley (2009); Yu et al. (2013)]. The analysis of words in the titles and abstracts of papers is described as a useful instrument by Leydesdorff and Zaal (1988), because authors are precise in their selection of words. In the case of keywords, authors have also stressed the use of co-word analysis as an option to display and map the literature in a particular scientific field [Zhang et al. (2012); Ravikumar et al. (2015)].

In the field of medical research, the use of MESH appears when the PubMed database is used as the source of papers that researchers use to obtain data. For example, Siqueiros-García et al. (2014) utilised network analysis to evaluate differences in the number of nodes (MESH) and edges between periods. They used 1-mode networks and calculated centrality measures, average shortest path length and number of neighbours. With these measures, they observed which MESH gained in connectivity with others over time. However, other authors like Zhang et al. (2012) preferred to make queries in the Web of Science instead of in more specialised databases, such as PubMed.

The use of information in acknowledgments is less common than the use of citations. As a consequence, there is a lack of papers examining funding agencies which appear in acknowledgements [Vanderelst and Speybroeck (2013); Zhou and Tian (2014); Tahmooresnejad et al. (2015)]. This is the reason behind this paper as it aims to cover the gap in the analysis of funding agencies through acknowledgements in papers. To achieve this, our efforts centred on finding the answers to three questions:

Q1: How did co-funding patterns differ between 2003 and 2013?

Q2: How do funding patterns differ depending on NCI involvement and cross-national co-funding?

Q3: How do funding patterns differ depending on the MESH that agencies fund?

\section{Data}

The PubMed database enabled us to obtain all the papers available in the two topics under study: ovarian cancer and breast cancer. These were analysed separately in order to find similarities and differences. The queries used are shown below:

a) Topic=("breast neoplasms"[MeSH] OR ("breast"[All Fields] AND "neoplasms"[All Fields]) OR "breast neoplasms"[All Fields] OR ("breast"[All Fields] AND "cancer"[All Fields]) OR "breast cancer"[All Fields]) AND ("2009/04/21"[PDat] : "2014/04/19"[PDat] AND cancer[sb])

b) Topic=("ovarian neoplasms"[MeSH] OR ("ovarian"[All Fields] AND "neoplasms"[All Fields]) OR "ovarian neoplasms"[All Fields] OR ("ovarian"[All Fields] AND "cancer"[All Fields]) OR "ovarian cancer"[All Fields]) AND cancer[sb]

Data on funding agencies was obtained from the acknowledgments that appeared in the papers. To obtain the names of the agencies appearing in these acknowledgements, the numbers of grants were cleaned using the software VantagePoint [Porter and Cunningham (2005)]. This software was also used to clean the MESH and obtain 1-mode matrixes for agency co-funding and MESH co-occurrence, and 2-mode networks for agency-by-MESH co-occurrence. Ucinet6 software [Suominen (2014); Swar and Khan (2014); Kim et al. (2014)] was used for the Social Network Analysis.

Table 1 shows a summary of the records used in our analysis. Although information about funding depends on the period analysed (Figure 1), the database as a whole estimated that $18 \%$ of papers included information about funding agencies (Table 1). Network visualisation was carried out using Gephi 
[Bastian et al. (2009)] and VOSViewer software [van Eck and Waltman (2010)], which was also utilised for clustering the MESH. A summary of the steps followed is shown below:

1. Queries made in PubMed.

2. Two files were downloaded in text format, one for each topic, imported in VantagePoint software.

3. The information in acknowledgements was cleaned to extract research agencies using VantagePoint software.

4. A sub-data set was created for the years spanning from 2003 to 2013 for each topic using VantagePoint software.

5. For each year and topic, the agencies and MESH were listed to obtain relevant records and order the relevant records by importance, using VantagePoint software.

6. The matrices for each year and topic were developed, creating agency-by-agency, MESHby-agency and MESH-by-MESH matrices, using VantagePoint software.

7. Centrality measures were calculated using Ucinet6.

8. Networks of co-funding agencies were visualised using Gephi.

9. The MESH were clustered and networks were visualised using VOSViewer.

Table 1 . Summary of data used in the analysis

\begin{tabular}{lll}
\hline & Med1 (ovarian cancer) & Med 2 (breast cancer) \\
\hline Total records & 81,937 & 273,526 \\
Records that included funding details & $14,560(17.77 \%)$ & $48,948(17.9 \%)$ \\
Number of funding agencies & 65 & 91 \\
Funding agencies that coincide & 63 & 63 \\
Funding agencies that do not coincide & 28 & 2 \\
\hline
\end{tabular}

Source: own source from cleaned PubMed data

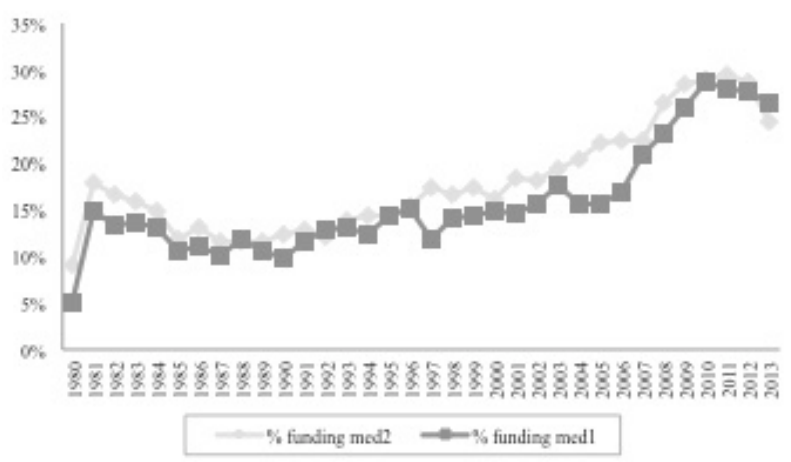

Fig. 1. Percentage of papers which give funding information by year. Source: own source from cleaned PubMed data

\section{Results}

Once the data had been cleaned with VantagePoint software, the first results obtained showed that the majority of funding agencies for the two topics were located in the United States (about 80\%), followed by the United Kingdom, Canada, Austria, Italy, Ireland, and in other European countries represented by the European Research Council.

Figures 2 to 5 show that the majority of the agencies funded breast cancer research first and then ovarian cancer research. Moreover, the number of agencies that funded research into both topics increased during the ten year period. 
Table 2 features a summary of the most important results obtained from the Social Network Analysis. It is obvious that the National Cancer Institute (NCI) is the most important funding agency for the two medical topics and the two periods analysed. Degree centrality also shows the importance of the National Centre for Research Resources (NCRR) for both topics, while the National Institute of General Medical Sciences (NIGMS) was present in ovarian cancer and the Public Health Service (PHS) emerged in breast cancer. The betweenness centrality of the NCRR, NIGMS and NIMH is also important. These agencies are central nodes for those accessing the NCI. This is also the case of the WHI and NCPDCID (Figure 2). Therefore, in figures 2 to 5 we can see that the main differences between 2003 and 2013 depended on:

a) The existence of cross-agency co-funding, and the appearance of the NCI as a co-funding agency,

b) The existence of cross-national co-funding, and

c) The number of participants involved in co-funding.

Table 2. Summary of Social Network Analysis. Centrality measures

\begin{tabular}{lllll}
\hline & Med1 Y2003 & Med1 Y2013 & Med2 Y2003 & Med2 Y2013 \\
\hline Network density & $21.57 \%$ & $18.5 \%$ & $16.9 \%$ & $23.6 \%$ \\
Centrality degree & NCI & NCI & NCI & NCI \\
& NIGMS & NCRR & NCRR & NCRR \\
& NCRR & NIGMS & & PHS \\
Closeness & NCI & NCI & NCI & NCI \\
& NIGMS & NCRR & NCRR & NCRR \\
& NCRR & NIGMS & & PHS \\
\multirow{5}{*}{ Betweenness } & NCI & NCI & NCI & NIGMS \\
& NCRR & NIGMS & NCRR & NIMH \\
& & & & NIGMS \\
\hline
\end{tabular}

NCI: National Cancer Institute; NCRR: National Center for Research Resources; NIGMS: National Institute of General Medical Sciences; PHS: Public Health Service; NIMH: National Institute of Mental Health; Source: own source from cleaned PubMed data

\subsection{Co-funded research into ovarian cancer}

Figure 2 and Figure 3 represent the evolution in co-funded research into ovarian cancer between 2003 and 2013. It is evident that the number of agencies that funded research in this topic increased over the period, and the number of links between agencies expanded. In order to better analyse the number of links and their patterns, cliques were calculated for every network. Each participant in the clique had ties with the rest of nodes which made up the clique.

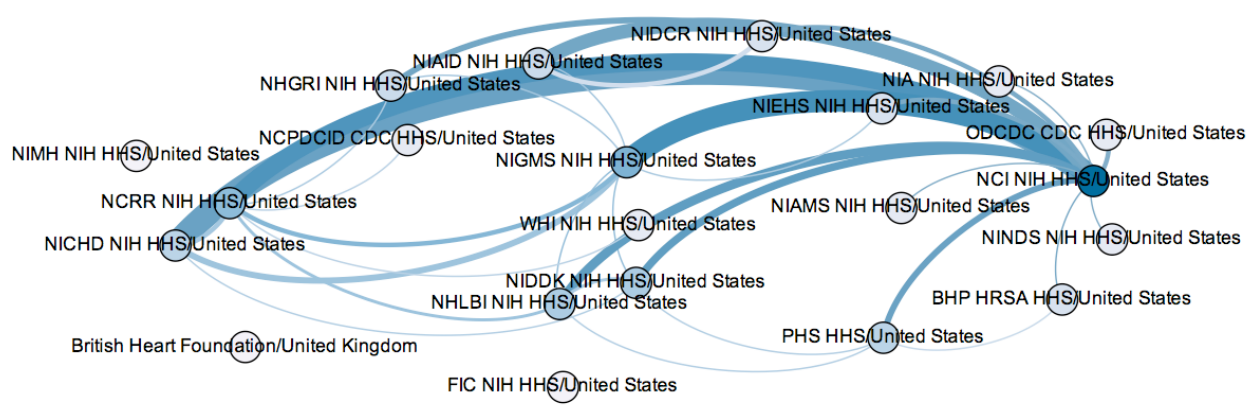


Fig. 2. Co-funded research into ovarian cancer in 2003. Visualisation using Gephi software. Nodes: 21; links: 33. Source: own source from cleaned PubMed data

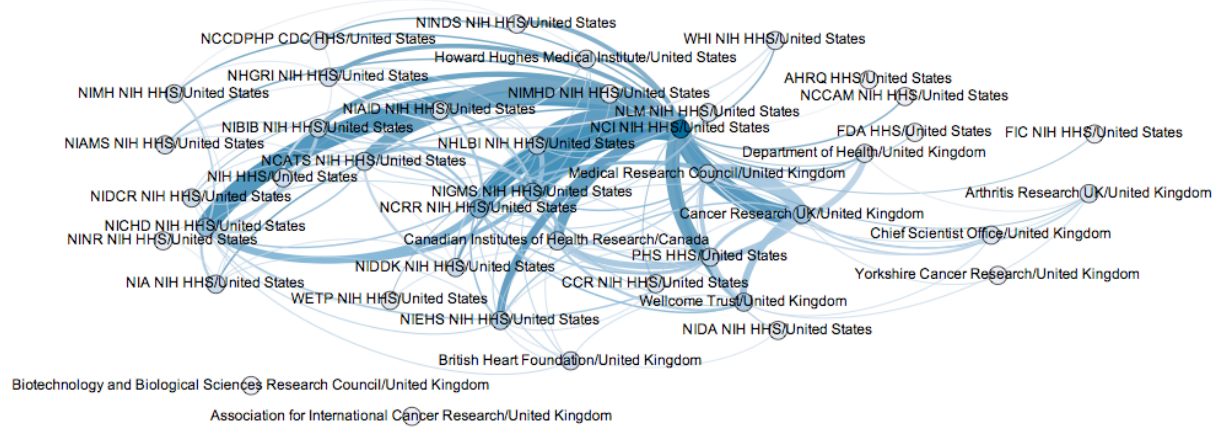

Fig.3. Co-funded research into ovarian cancer in 2013. Visualisation using Gephi software. Nodes: 42; links: 144. Source: own source from cleaned PubMed data

Next, we calculated the cliques where there were more than three funding organisations. We found 10 cliques for ovarian cancer in 2003 and 38 cliques in 2013:

1. NCI NIH HHS/United States; NICHD NIH HHS/United States: NCRR NIH HHS/United States; NIGMS NIH HHS/United States.

2. NCI NIH HHS/United States; NCRR NIH HHS/United States; NIGMS NIH HHS/United States; NHLBI NIH HHS/United States.

3. NCI NIH HHS/United States; NCRR NIH HHS/United States; NIGMS NIH HHS/United States; NHGRI NIH HHS/United States.

4. NCI NIH HHS/United States; NIGMS NIH HHS/United States; NIAID NIH HHS/United States.

5. NCI NIH HHS/United States; NICHD NIH HHS/United States; NIGMS NIH HHS/United States; NIDDK NIH HHS/United States.

6. NCI NIH HHS/United States; NIGMS NIH HHS/United States; NIDDK NIH HHS/United States; NHLBI NIH HHS/United States.

7. NCI NIH HHS/United States; NIGMS NIH HHS/United States; NIEHS NIH HHS/United States.

8. NCI NIH HHS/United States; NIDDK NIH HHS/United States; NHLBI NIH HHS/United States; PHS HHS/United States.

9. NCI NIH HHS/United States; PHS HHS/United States; BHP HRSA HHS/United States.

10. NCI NIH HHS/United States; NIAID NIH HHS/United States; NIDCR NIH HHS/United States.

We use the term clique in the strictest sense of the word, which means that each participant in the clique has ties with the rest of nodes which form the clique. When comparing the year 2003 with 2013 we can see that agencies that were not directly connected to the NCI in the network in 2003 do not appear in any clique (WHI and NCPDCID). However, while some agencies were not connected directly to the NCI in 2013, they do appear in cliques (NINR, British Heart Foundation). In addition, in 2003 the NCI was involved in every clique, while in 2013 it only appeared in 35 cliques ( $92 \%$ of cliques). Moreover, in 2003 all the cliques were formed by United States agencies, while in 2013 we observe that 11 cliques incorporated cross-national co-funding ( $28.9 \%$ of cliques). The nations involved in these 11 cliques were United States, Canada and United Kingdom (these three nations appeared in four cliques, United States and United Kingdom in six cliques, and United States and Canada in one clique). We only included the 
cliques where cross-nation funding appeared. The complete results about cliques can be consulted in Annex 1.

- C1: NCI NIH HHS/United States; Canadian Institutes of Health Research/Canada; NICHD NIH HHS/United States; NIGMS NIH HHS/United States; NCRR NIH HHS/United States; PHS HHS/United States; NIEHS NIH HHS/United States.

- C4: NCI NIH HHS/United States; Canadian Institutes of Health Research/Canada; Cancer Research UK/United Kingdom; NIGMS NIH HHS/United States; NCRR NIH HHS/United States; Medical Research Council/United Kingdom; PHS HHS/United States; Wellcome Trust/United Kingdom.

- C5: NCI NIH HHS/United States; Canadian Institutes of Health Research/Canada; Cancer Research UK/United Kingdom; NIGMS NIH HHS/United States; NCRR NIH HHS/United States; PHS HHS/United States; NIEHS NIH HHS/United States.

- C10: NCI NIH HHS/United States; Cancer Research UK/United Kingdom; NIGMS NIH HHS/United States; NIDDK NIH HHS/United States.

- C13: NCI NIH HHS/United States; Cancer Research UK/United Kingdom; Medical Research Council/United Kingdom; Department of Health/United Kingdom; Arthritis Research UK/United Kingdom.

- C28: NCI NIH HHS/United States; Cancer Research UK/United Kingdom; Medical Research Council/United Kingdom; Wellcome Trust/United Kingdom; Chief Scientist Office/United Kingdom.

- C31: NCI NIH HHS/United States; Wellcome Trust/United Kingdom; NIDCR NIH HHS/United States; WETP NIH HHS/United States.

- C33: NCI NIH HHS/United States; Cancer Research UK/United Kingdom; Medical Research Council/United Kingdom; Wellcome Trust/United Kingdom; Arthritis Research UK/United Kingdom.

- C35: NCI NIH HHS/United States; Cancer Research UK/United Kingdom; NCRR NIH HHS/United States; NIEHS NIH HHS/United States; CCR NIH HHS/United States.

- C36: Canadian Institutes of Health Research/Canada; NICHD NIH HHS/United States; NIGMS NIH HHS/United States; NCRR NIH HHS/United States; NIEHS NIH HHS/United States; British Heart Foundation/United Kingdom.

- C37: Canadian Institutes of Health Research/Canada; NIGMS NIH HHS/United States; NCRR NIH HHS/United States; Wellcome Trust/United Kingdom; British Heart Foundation/United Kingdom.

For co-funding in ovarian cancer, we can conclude that:

a) In 2003, the $\mathrm{NCI}$ was involved in every clique, while in 2013 it appeared in 35 cliques ( $92 \%$ of all cliques).

b) In 2003, all of the cliques were formed by United States agencies, while in 2013 we observe that 11 cliques incorporated cross-national co-funding ( $28.9 \%$ of cliques).

c) The nations involved in these 11 cliques were United States, Canada and United Kingdom. These three nations appeared in four cliques, United States and United Kingdom in six cliques, and United States and Canada in one clique.

\subsection{Co-funded research into ovarian cancer}

Figure 4 and Figure 5 represent the evolution in co-funded research into breast cancer between 2003 and 2013. It is clear that the number of agencies that funded research into this topic increased over the period, and that the number of links between agencies grew, as the cliques illustrate. It is important to point out that the agencies that were only related to the NCI in 2003 appeared to be connected to more agencies in 2013, demonstrating that links between agencies increased over the period. This is shown in Figures 4 and 5 . 


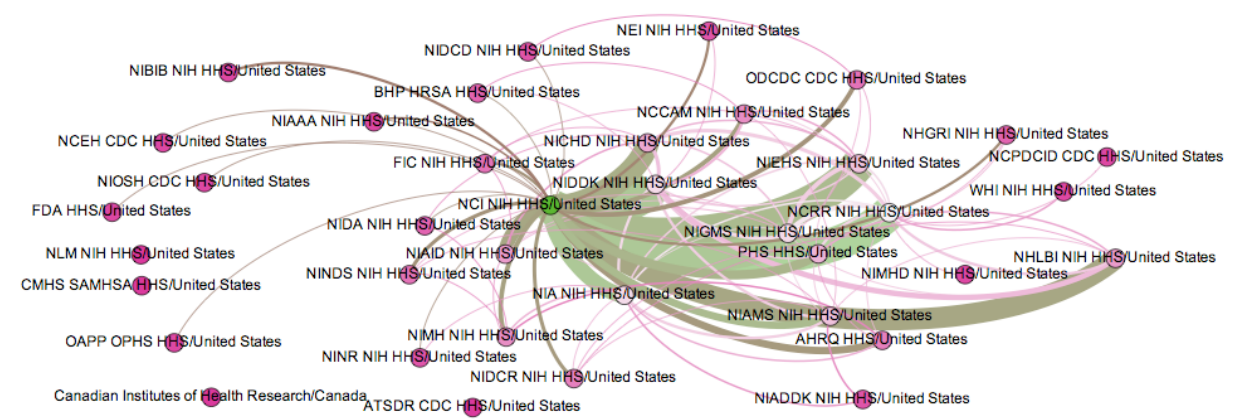

Fig.4. Co-funded research into breast cancer in 2003. Visualisation using Gephi software. Nodes: 38; links: 95. Source: own source from cleaned PubMed data

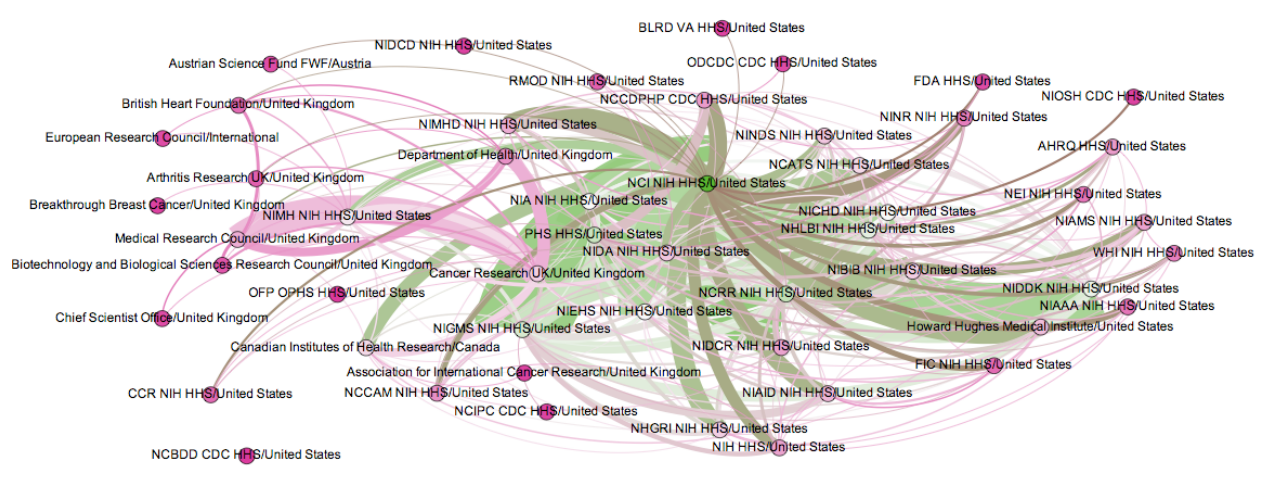

Fig.5. Co-funded research into breast cancer in 2013. Visualisation using Gephi software. Nodes: 51; links: 278. Source: own source from cleaned PubMed data

In terms of breast cancer, there were 32 cliques which featured more than three funding organisations in 2003, whilst this rose to 70 in 2013:

1. NCI NIH HHS/United States; NIDDK NIH HHS/United States; NCRR NIH HHS/United States; NIEHS NIH HHS/United States; NIGMS NIH HHS/United States; NICHD NIH HHS/United States.

2. NCI NIH HHS/United States; NIDDK NIH HHS/United States; NCRR NIH HHS/United States; NIEHS NIH HHS/United States; NIGMS NIH HHS/United States; NIA NIH HHS/United States.

3. NCI NIH HHS/United States; NIDDK NIH HHS/United States; NCRR NIH HHS/United States; NIEHS NIH HHS/United States; PHS HHS/United States.

4. NCI NIH HHS/United States; NIDDK NIH HHS/United States; NCRR NIH HHS/United States; NIEHS NIH HHS/United States; NCCAM NIH HHS/United States.

5. NCI NIH HHS/United States; NIDDK NIH HHS/United States; NCRR NIH HHS/United States; NIGMS NIH HHS/United States; NHLBI NIH HHS/United States.

6. NCI NIH HHS/United States; NIDDK NIH HHS/United States; NCRR NIH HHS/United States; NHLBI NIH HHS/United States; PHS HHS/United States.

7. NCI NIH HHS/United States; NIDDK NIH HHS/United States; NIGMS NIH HHS/United States; NHLBI NIH HHS/United States; NIAMS NIH HHS/United States.

8. NCI NIH HHS/United States; NIDDK NIH HHS/United States; NIGMS NIH HHS/United States; NIA NIH HHS/United States; NIAMS NIH HHS/United States.

9. NCI NIH HHS/United States; NIDDK NIH HHS/United States; NHLBI NIH HHS/United States; PHS HHS/United States; NIAMS NIH HHS/United States. 
10. NCI NIH HHS/United States; NIDDK NIH HHS/United States; NIAMS NIH HHS/United States; NCCAM NIH HHS/United States.

11. NCI NIH HHS/United States; NIDDK NIH HHS/United States; NEI NIH HHS/United States.

12. NCI NIH HHS/United States; NIDDK NIH HHS/United States; NCCAM NIH HHS/United States; BHP HRSA HHS/United States.

13. NCI NIH HHS/United States; NIGMS NIH HHS/United States; NICHD NIH HHS/United States; NIAID NIH HHS/United States.

14. NCI NIH HHS/United States; NIGMS NIH HHS/United States; NIA NIH HHS/United States; NIAID NIH HHS/United States.

15. NCI NIH HHS/United States; PHS HHS/United States; NIAID NIH HHS/United States.

16. NCI NIH HHS/United States; NIA NIH HHS/United States; NIAID NIH HHS/United States; NIMH NIH HHS/United States.

17. NCI NIH HHS/United States; NICHD NIH HHS/United States; NIAID NIH HHS/United States; FIC NIH HHS/United States.

18. NCI NIH HHS/United States; NCRR NIH HHS/United States; NIA NIH HHS/United States; AHRQ HHS/United States.

19. NCI NIH HHS/United States; NIA NIH HHS/United States; AHRQ HHS/United States; NIMH NIH HHS/United States.

20. NCI NIH HHS/United States; NCRR NIH HHS/United States; PHS HHS/United States; AHRQ HHS/United States.

21. NCI NIH HHS/United States; NIEHS NIH HHS/United States; NIGMS NIH HHS/United States; ODCDC CDC HHS/United States.

22. NCI NIH HHS/United States; ODCDC CDC HHS/United States; NIDCD NIH HHS/United States.

23. NCI NIH HHS/United States; NCRR NIH HHS/United States; NIGMS NIH HHS/United States; NHGRI NIH HHS/United States.

24. NCI NIH HHS/United States; NIMH NIH HHS/United States; NIDA NIH HHS/United States.

25. NCI NIH HHS/United States; NIMH NIH HHS/United States; NINDS NIH HHS/United States

26. NCI NIH HHS/United States; NIGMS NIH HHS/United States; NIAMS NIH HHS/United States; NINDS NIH HHS/United States.

27. NCI NIH HHS/United States; NHLBI NIH HHS/United States; PHS HHS/United States; NIAMS NIH HHS/United States; NIDCR NIH HHS/United States.

28. NCI NIH HHS/United States; NIA NIH HHS/United States; NIAMS NIH HHS/United States NIDCR NIH HHS/United States.

29. NCI NIH HHS/United States; NIEHS NIH HHS/United States; NICHD NIH HHS/United States; FIC NIH HHS/United States.

30. NCI NIH HHS/United States; NIA NIH HHS/United States; NINR NIH HHS/United States.

31. NCI NIH HHS/United States; NICHD NIH HHS/United States; NIDA NIH HHS/United States.

32. NIA NIH HHS/United States; NIAMS NIH HHS/United States; NIADDK NIH HHS/United States.

A comparison of 2003 and 2013 reveals the importance of the NCI, which appeared in 31 cliques in 2003 and in 67 in 2013. Moreover, in 2003 all the cliques were formed by United States agencies, while in 2013 we can see that 25 cliques incorporated cross-national co-funding (36\% of cliques). The nations involved in these 25 cliques were United States, Canada, United Kingdom, Austria and the European Research Council (United States and Canada appeared in 12 cliques; United States and United Kingdom in seven cliques; United States, United Kingdom and Canada in four cliques; United States and Austria in one clique; and United States, United Kingdom and the European Research Council in one clique). We only included the cliques where cross-national funding appeared. The complete results about cliques can be consulted in Annex 2.

- $\quad$ C11: NCI NIH HHS/United States; NCRR NIH HHS/United States; NIGMS NIH HHS/United States; Canadian Institutes of Health Research/Canada; PHS HHS/United States; NIDDK NIH HHS/United States; NIA NIH HHS/United States; NIAID NIH HHS/United States.

- $\quad$ C12: NCI NIH HHS/United States; NCRR NIH HHS/United States; NIGMS NIH HHS/United States; Canadian Institutes of Health Research/Canada; PHS HHS/United States; NIDDK NIH HHS/United States; NIA NIH HHS/United States; NIDCR NIH HHS/United States.

- $\quad$ C13: NCI NIH HHS/United States; NCRR NIH HHS/United States; NIGMS NIH HHS/United States; Canadian Institutes of Health Research/Canada; PHS HHS/United States; NIDDK NIH HHS/United States; NIA NIH HHS/United States; NCCAM NIH HHS/United States.

- $\quad$ C14: NCI NIH HHS/United States; NCRR NIH HHS/United States; NIGMS NIH HHS/United States; Canadian Institutes of Health Research/Canada; PHS HHS/United States; NIDDK NIH HHS/United States; NIEHS NIH HHS/United States; NHGRI NIH HHS/United States.

- $\quad$ C15: NCI NIH HHS/United States; NCRR NIH HHS/United States; NIGMS NIH HHS/United States; Canadian Institutes of Health Research/Canada; PHS HHS/United States; NIDDK NIH HHS/United States; NIEHS NIH HHS/United States; NCCAM NIH HHS/United States.

- $\quad$ C16: NCI NIH HHS/United States; NCRR NIH HHS/United States; NIGMS NIH HHS/United States; Canadian Institutes of Health Research/Canada; PHS HHS/United States; NIDDK NIH HHS/United States; NHGRI NIH HHS/United States; NIAID NIH HHS/United States.

- $\quad$ C22: NCI NIH HHS/United States; NCRR NIH HHS/United States; NIGMS NIH HHS/United States; Canadian Institutes of Health Research/Canada; PHS HHS/United States; Cancer Research UK/United Kingdom; NIEHS NIH HHS/United States. 
- $\quad$ C23: NCI NIH HHS/United States; NCRR NIH HHS/United States; NIGMS NIH HHS/United States; Canadian Institutes of Health Research/Canada; PHS HHS/United States; Cancer Research UK/United Kingdom; NIA NIH HHS/United States.

- $\quad$ C24: NCI NIH HHS/United States; NCRR NIH HHS/United States; NIGMS NIH HHS/United States; PHS HHS/United States; Cancer Research UK/United Kingdom; Howard Hughes Medical Institute/United States.

- $\quad$ C25: NCI NIH HHS/United States; NCRR NIH HHS/United States; PHS HHS/United States; Cancer Research UK/United Kingdom; NIEHS NIH HHS/United States; CCR NIH HHS/United States.

- $\quad$ C38: NCI NIH HHS/United States; NCRR NIH HHS/United States; NIGMS NIH HHS/United States; Canadian Institutes of Health Research/Canada; NIA NIH HHS/United States; NIAID NIH HHS/United States; NIDA NIH HHS/United States.

- $\quad$ C39: NCI NIH HHS/United States; NCRR NIH HHS/United States; NIGMS NIH HHS/United States; Canadian Institutes of Health Research/Canada; NIEHS NIH HHS/United States; NIDA NIH HHS/United States.

- $\quad$ C44: NCI NIH HHS/United States; NIGMS NIH HHS/United States; Canadian Institutes of Health Research/Canada; PHS HHS/United States; Cancer Research UK/United Kingdom; NIA NIH HHS/United States; Medical Research Council/United Kingdom.

- $\quad$ C45: NCI NIH HHS/United States; NIGMS NIH HHS/United States; Canadian Institutes of Health Research/Canada; Cancer Research UK/United Kingdom; NIA NIH HHS/United States; Medical Research Council/United Kingdom; NIMH NIH HHS/United States.

- $\quad$ C46: NCI NIH HHS/United States; NIGMS NIH HHS/United States; PHS HHS/United States; Cancer Research UK/United Kingdom; Medical Research Council/United Kingdom; Department of Health/United Kingdom.

- $\quad$ C47: NCI NIH HHS/United States; NIGMS NIH HHS/United States; Cancer Research UK/United Kingdom; Medical Research Council/United Kingdom; NIMH NIH HHS/United States; Department of Health/United Kingdom.

- C48: NCI NIH HHS/United States; Cancer Research UK/United Kingdom; Medical Research Council/United Kingdom; NIMH NIH HHS/United States; Department of Health/United Kingdom; British Heart Foundation/United Kingdom.

- C49: NCI NIH HHS/United States; Cancer Research UK/United Kingdom; Medical Research Council/United Kingdom; Department of Health/United Kingdom; Arthritis Research UK/United Kingdom.

- $\quad$ C53: NCI NIH HHS/United States; NIGMS NIH HHS/United States; Canadian Institutes of Health Research/Canada; NIA NIH HHS/United States; NIMH NIH HHS/United States; NIDA NIH HHS/United States.

- $\quad$ C57: NCI NIH HHS/United States; NIGMS NIH HHS/United States; Canadian Institutes of Health Research/Canada; NIMH NIH HHS/United States; NHGRI NIH HHS/United States.

- $\quad$ C58: NCI NIH HHS/United States; NIMH NIH HHS/United States; Austrian Science Fund FWF/Austria.

- C61: NCI NIH HHS/United States; Canadian Institutes of Health Research/Canada; PHS HHS/United States; NIDDK NIH HHS/United States; NIA NIH HHS/United States; NCCDPHP CDC HHS/United States.

- $\quad$ C63: NCI NIH HHS/United States; Canadian Institutes of Health Research/Canada; PHS HHS/United States; NIDDK NIH HHS/United States; NIEHS NIH HHS/United States; NCCDPHP CDC HHS/United States.

- C68: Cancer Research UK/United Kingdom; Medical Research Council/United Kingdom; NIMH NIH HHS/United States; Biotechnology and Biological Sciences Research Council/United Kingdom.

- C69: Cancer Research UK/United Kingdom; Medical Research Council/United Kingdom; Chief Scientist Office/United Kingdom.

- C70: NIMH NIH HHS/United States; Department of Health/United Kingdom; European Research Council/International.

For co-funding in breast cancer, we can conclude that:

a) The NCI is important, as it appeared in 31 cliques in 2003 and in 67 in 2013.

b) In 2003, all of the cliques were formed by United States agencies, while in 2013 we observe that 25 cliques incorporated cross-national co-funding (36\% of cliques).

c) The nations involved in these 25 cliques were United States, Canada, United Kingdom, Austria and the European Research Council. United States and Canada appeared in 12 cliques; United States and United Kingdom in seven cliques; United States, United Kingdom and Canada in four cliques; United States and Austria in one clique; United States, United Kingdom and the European Research Council in one clique.

Table 3 summarises the main results for both types of cancer, indicating that the NCI is the most important agency in both cases; this has also been demonstrated with cliques. An important difference found between ovarian and breast cancer research is that in ovarian research cross-national co-funding between the United States and United Kingdom prevailed (6 cliques), while in breast research the dominant linkage occurred between United States and Canada (12 cliques). 


\begin{tabular}{lllll}
\hline Non co-funding agencies (isolated in network) & 3 & 2 & 4 & 2 \\
Cross-agency with NCI (number of cliques) & $10 / 10$ & $35 / 38$ & $31 / 32$ & $67 / 70$ \\
Cross-agency without NCI (number of cliques) & 0 & 3 & 1 & 3 \\
Cross-national co-funding (number of cliques) & 0 & $11 / 38(29 \%)$ & 0 & $25 / 70(36 \%)$ \\
& & United States, & Canada, & Canited States, \\
& & United Kingdom & & United Kingdom, Austria, \\
& & & European Research Council \\
\hline
\end{tabular}

Source: own source from cleaned PubMed data

\subsection{Evolution in the funding of MESH}

This section analyses the most important medical subject headings (MESH) funded and the evolution of these terms in the two medical research fields under study. It then explores the headings which were most significant depending on the respective funding agency. In all the cases, only the terms with 50 records or more were selected.

The MESH that appeared in papers in which acknowledgments included agencies supporting research are shown in Tables 3 and 4 . As there were too many terms, the tables only included the first 30 headings (by order of importance). In Table 3, the MESH for ovarian cancer research indicate that the five most common terms were the same for the two years analysed: "humans", "female", "middle-aged", "adult", and "aged". However, if we compare 2013 to 2003, we can see that terms like "cell line, tumour", "gene expression regulation", and "cell proliferation" increased in importance over the period. However, terms like "male" and "immunohistochemistry" were less important in 2013 than in 2003. Table 4 shows that the five most important terms in breast cancer did not change between 2003 and 2013. These terms were "humans", "female", "middle-aged", "adult" and "aged". A comparison of the two reference years showed that the terms which became more popular in the list over the period were "cell line, tumour", "young adult", "cell proliferation", "receptor, erbB-2/metabolism" and "receptors, oestrogen/metabolism".

Table 3. Ranking of MESH for ovarian research in 2003 and 2013

\begin{tabular}{|c|c|c|c|c|c|}
\hline Order & $\begin{array}{l}\text { Records med1 } \\
\text { Y2003 }\end{array}$ & MESH & Order & $\begin{array}{l}\text { Records } \\
\text { med1 Y2013 }\end{array}$ & MESH \\
\hline 1 & 2508 & Humans & 1 & 2541 & Humans \\
\hline 2 & 2383 & Female & 2 & 2396 & Female \\
\hline 3 & 902 & Middle-Aged & 3 & 960 & Middle-Aged \\
\hline 4 & 832 & Adult & 4 & 817 & Adult \\
\hline 5 & 655 & Aged & 5 & 714 & Aged \\
\hline 19 & 148 & Cell Line, Tumour & 6 & 501 & Cell Line, Tumour \\
\hline 6 & 356 & Animals & 7 & 430 & Animals \\
\hline 10 & 230 & Prognosis & 8 & 327 & Prognosis \\
\hline 14 & 188 & Aged, 80 and over & 9 & 318 & Aged, 80 and over \\
\hline 7 & 286 & Neoplasm Staging & 10 & 317 & Neoplasm Staging \\
\hline 13 & 199 & Mice & 11 & 289 & Mice \\
\hline 8 & 280 & Male & 12 & 243 & Male \\
\hline \multirow[t]{2}{*}{16} & 163 & Retrospective Studies & 13 & 232 & Retrospective Studies \\
\hline & & & 14 & 223 & Young Adult \\
\hline 11 & 220 & Treatment Outcome & 15 & 203 & Treatment Outcome \\
\hline 28 & 104 & $\begin{array}{l}\text { Gene Expression } \\
\text { Regulation, Neoplastic }\end{array}$ & 16 & 189 & $\begin{array}{l}\text { Gene Expression } \\
\text { Regulation, Neoplastic }\end{array}$ \\
\hline
\end{tabular}




\begin{tabular}{|c|c|c|c|c|c|}
\hline 17 & 154 & Risk Factors & 17 & 184 & Risk Factors \\
\hline 12 & 208 & Immunohistochemistry & 18 & 149 & Immunohistochemistry \\
\hline 15 & 166 & Adolescent & 19 & 145 & Adolescent \\
\hline 37 & 83 & Disease-Free Survival & 20 & 140 & Disease-Free Survival \\
\hline 44 & 71 & Follow-Up Studies & 21 & 137 & Follow-Up Studies \\
\hline 26 & 112 & Mutation & 22 & 135 & Mutation \\
\hline 42 & 72 & Case-Control Studies & 23 & 125 & Case-Control Studies \\
\hline \multirow[t]{3}{*}{31} & 99 & Survival Rate & 24 & 125 & Survival Rate \\
\hline & & & 25 & 123 & $\begin{array}{l}\text { Cell Proliferation/drug } \\
\text { effects }\end{array}$ \\
\hline & & & 26 & 118 & Neoplasm Grading \\
\hline 51 & 66 & Mice, Nude & 27 & 104 & Mice, Nude \\
\hline 30 & 100 & $\begin{array}{l}\text { Drug Resistance, } \\
\text { Neoplasm }\end{array}$ & 28 & 102 & Drug Resistance, Neoplasm \\
\hline \multirow[t]{2}{*}{830} & 3 & Cell Proliferation & 29 & 101 & Cell Proliferation \\
\hline & & & 30 & 101 & Kaplan-Meier Estimate \\
\hline
\end{tabular}

Source: own source from cleaned PubMed data

Table 4. Ranking of MESH for ovarian research in 2003 and 2013

\begin{tabular}{|c|c|c|c|c|c|}
\hline $\begin{array}{l}\text { Ord } \\
\text { er }\end{array}$ & $\begin{array}{l}\text { Records med2 } \\
\text { Y2003 }\end{array}$ & MESH & $\begin{array}{l}\text { Ord } \\
\text { er }\end{array}$ & $\begin{array}{l}\text { Records med2 } \\
\text { Y2013 }\end{array}$ & MESH \\
\hline 1 & 8810 & Humans & 1 & 8059 & Humans \\
\hline 2 & 7141 & Female & 2 & 7083 & Female \\
\hline 3 & 3375 & Middle-aged & 3 & 3033 & Middle-aged \\
\hline 4 & 2687 & Adult & 4 & 2461 & Adult \\
\hline 5 & 2463 & Aged & 5 & 2270 & Aged \\
\hline 20 & 456 & Cell Line, Tumour & 6 & 1472 & Cell Line, Tumour \\
\hline 7 & 1213 & Animals & 7 & 1430 & Animals \\
\hline 6 & 1230 & Male & 8 & 1053 & Male \\
\hline 12 & 658 & Mice & 9 & 967 & Mice \\
\hline 9 & 833 & Aged, 80 and over & 10 & 935 & Aged, 80 and over \\
\hline 11 & 728 & Prognosis & 11 & 876 & Prognosis \\
\hline 10 & 814 & Risk Factors & 12 & 655 & Risk Factors \\
\hline 14 & 552 & Neoplasm Staging & 13 & 640 & Neoplasm Staging \\
\hline 13 & 598 & Treatment Outcome & 14 & 633 & Treatment Outcome \\
\hline 19 & 478 & Retrospective Studies & 15 & 562 & Retrospective Studies \\
\hline 23 & 362 & $\begin{array}{l}\text { Gene Expression Regulation, } \\
\text { Neoplastic }\end{array}$ & 16 & 561 & $\begin{array}{l}\text { Gene Expression Regulation, } \\
\text { Neoplastic }\end{array}$ \\
\hline \multirow{2}{*}{$\begin{array}{l}320 \\
1\end{array}$} & 3 & Young Adult & 17 & 515 & Young Adult \\
\hline & & & 18 & 504 & MCF-7 Cells \\
\hline \multirow[t]{2}{*}{24} & 347 & Follow-Up Studies & 19 & 495 & Follow-Up Studies \\
\hline & & & 20 & 388 & Cell Proliferation/drug effects \\
\hline $\begin{array}{l}198 \\
6\end{array}$ & 5 & Cell Proliferation & 21 & 357 & Cell Proliferation \\
\hline 15 & 550 & Time Factors & 22 & 353 & Time Factors \\
\hline 16 & 538 & Immunohistochemistry & 23 & 342 & Immunohistochemistry \\
\hline 22 & 373 & Lymphatic Metastasis & 24 & 341 & Lymphatic Metastasis \\
\hline
\end{tabular}




\begin{tabular}{|c|c|c|c|c|c|}
\hline 165 & 81 & Receptor, erbB-2/metabolism & 25 & 338 & Receptor, erbB-2/metabolism \\
\hline 72 & 172 & Receptors, Estrogen/metabolism & 26 & 333 & Receptors, Estrogen/metabolism \\
\hline 50 & 236 & Neoplasm Invasiveness & 27 & 328 & Neoplasm Invasiveness \\
\hline 46 & 253 & Disease-Free Survival & 28 & 327 & Disease-Free Survival \\
\hline 29 & 312 & Prospective Studies & 29 & 311 & Prospective Studies \\
\hline 28 & 316 & Case-Control Studies & 30 & 309 & Case-Control Studies \\
\hline
\end{tabular}

Source: own source from cleaned PubMed data

Networks of co-occurrence in MESH are presented in Figures 6 to 9, where differences in networks represent an evolution in the position of the nodes and their linkages. Visualisation was carried out using VOSViewer, which allowed us to cluster words. Figure 6 shows the co-MESH for 2003 in ovarian cancer, while Figure 7 represents 2013. The VOSViewer software grouped the 71 terms from 2003 into five clusters, and the 81 terms for 2013 into four clusters. For example, the first cluster included terms like "humans", "female" and "tumour cell, cultured" in both years, while the second cluster grouped terms like "middle-aged", "adult", "aged" and "prognosis". In breast cancer, the software divided the 281 terms for 2003 into six clusters, and the 244 terms for 2013 into four clusters. It also clustered terms like "humans" and "female" in the two years, but not with the same words as in ovarian cancer.

Moreover, in 2003, eigenvector centrality for ovarian cancer was higher for the MESH "humans", "female", "middle-aged", "adult" and "male". These terms also showed high closeness and betweenness. In 2013, the eigenvector centrality, closeness, and betweenness were highest for "humans", "female", "middle-aged" and "animals". In the case of breast cancer, the highest values were for "humans" and "female", both for 2003 and 2013. In order to better detect the importance of the MESH, Tables 5 to 8 show which of them were funded by the most important research agencies. We tried to ascertain whether there was a coincidence between these centrality measures and the MESH that the most important agencies funded.

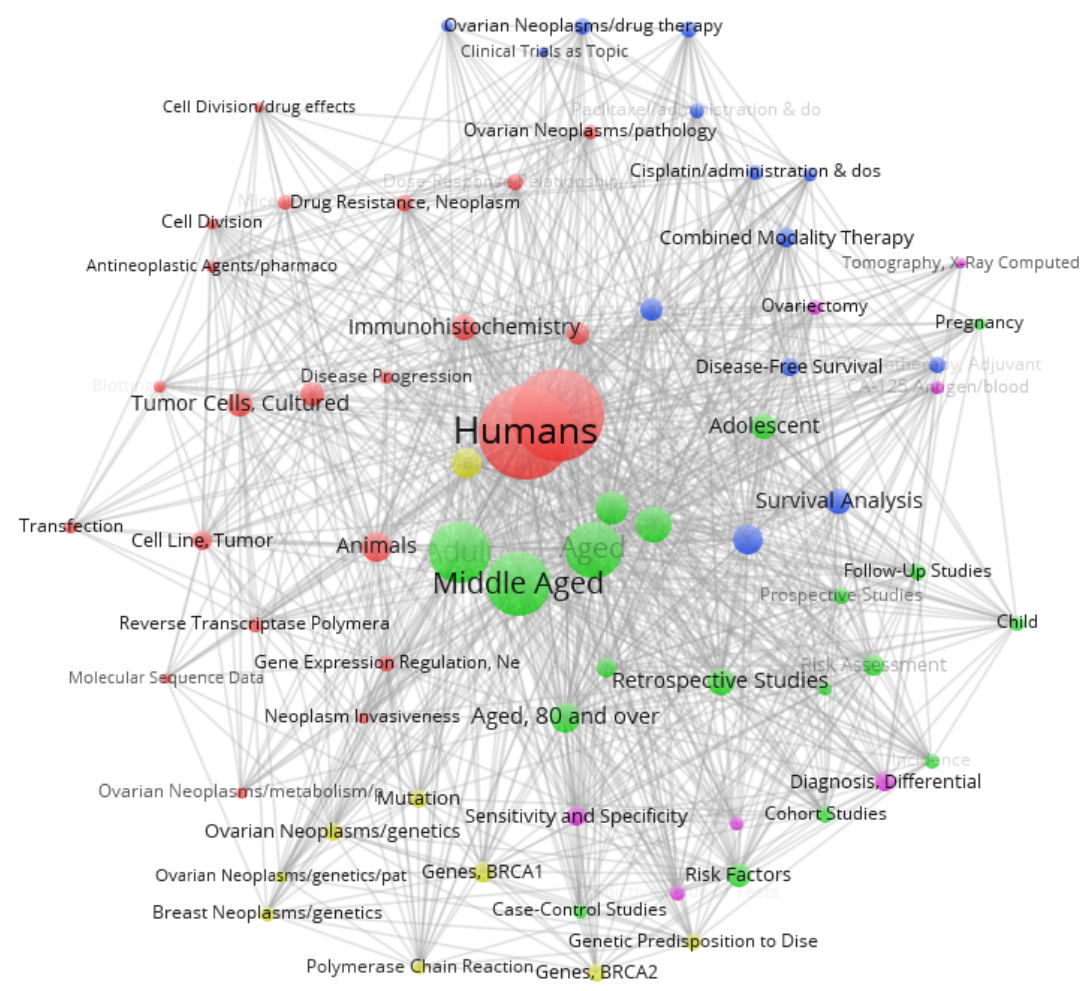


Figure 6. Co-occurrence in MESH for ovarian cancer research in 2003. Visualisation using VOSViewer software. Nodes: 71; links: 1881. Source: own source from cleaned PubMed data

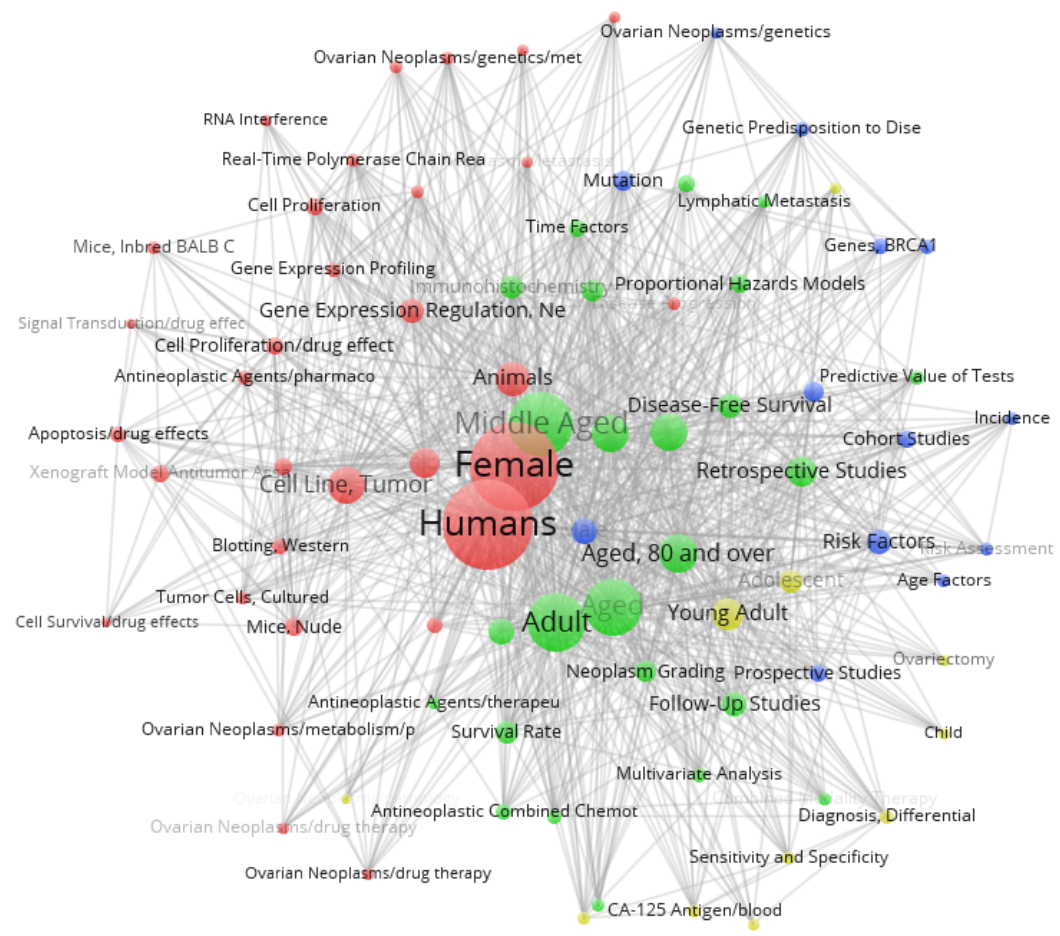

Figure 7. Co-occurrence in MESH for ovarian cancer research in 2013. Visualisation using VOSViewer software. Nodes: 81; links: 2484. Source: own source from cleaned PubMed data

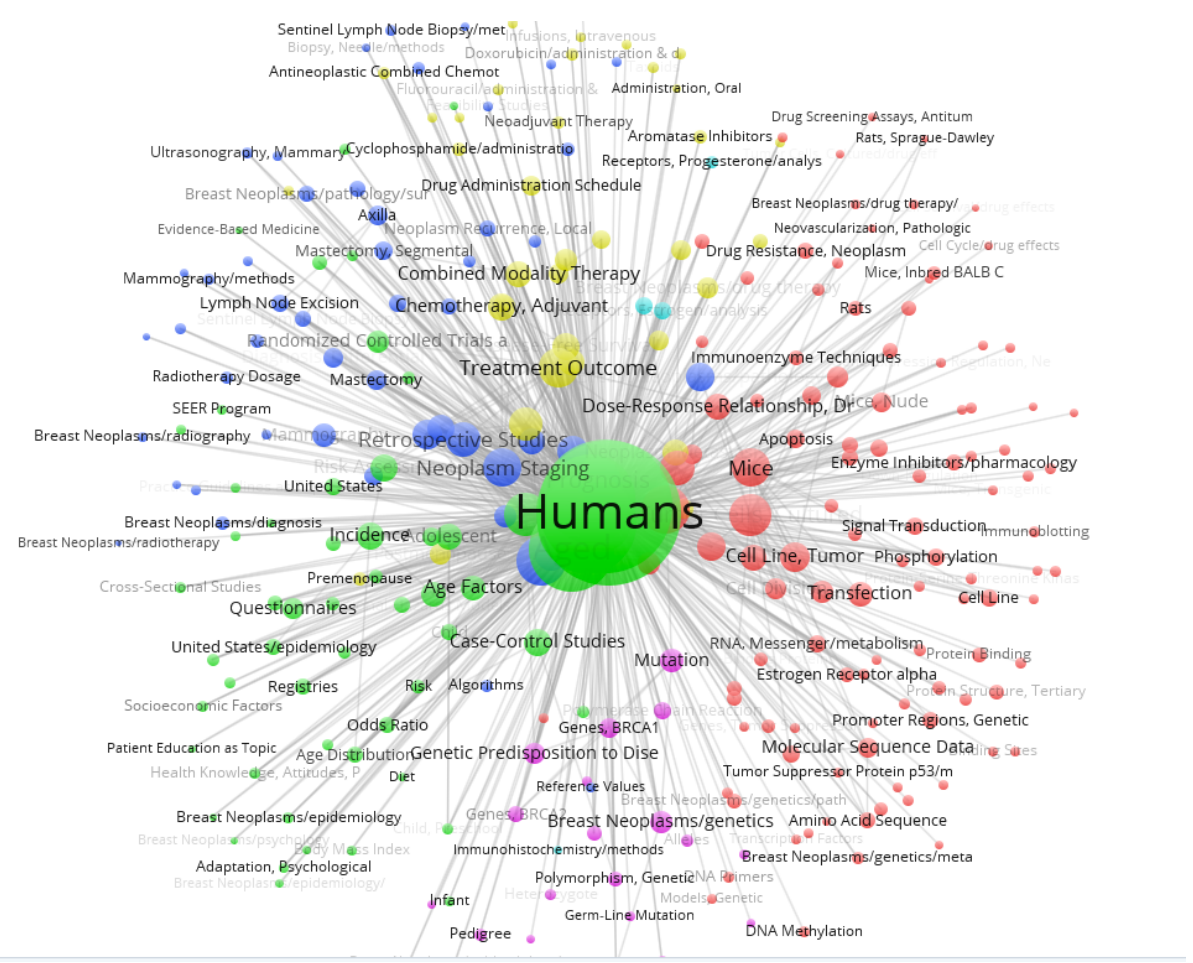


Figure 8. Co-occurrence in MESH for breast cancer research in 2003. Visualisation using VOSViewer software. Nodes: 281; links: 19045. Source: own source from cleaned PubMed data

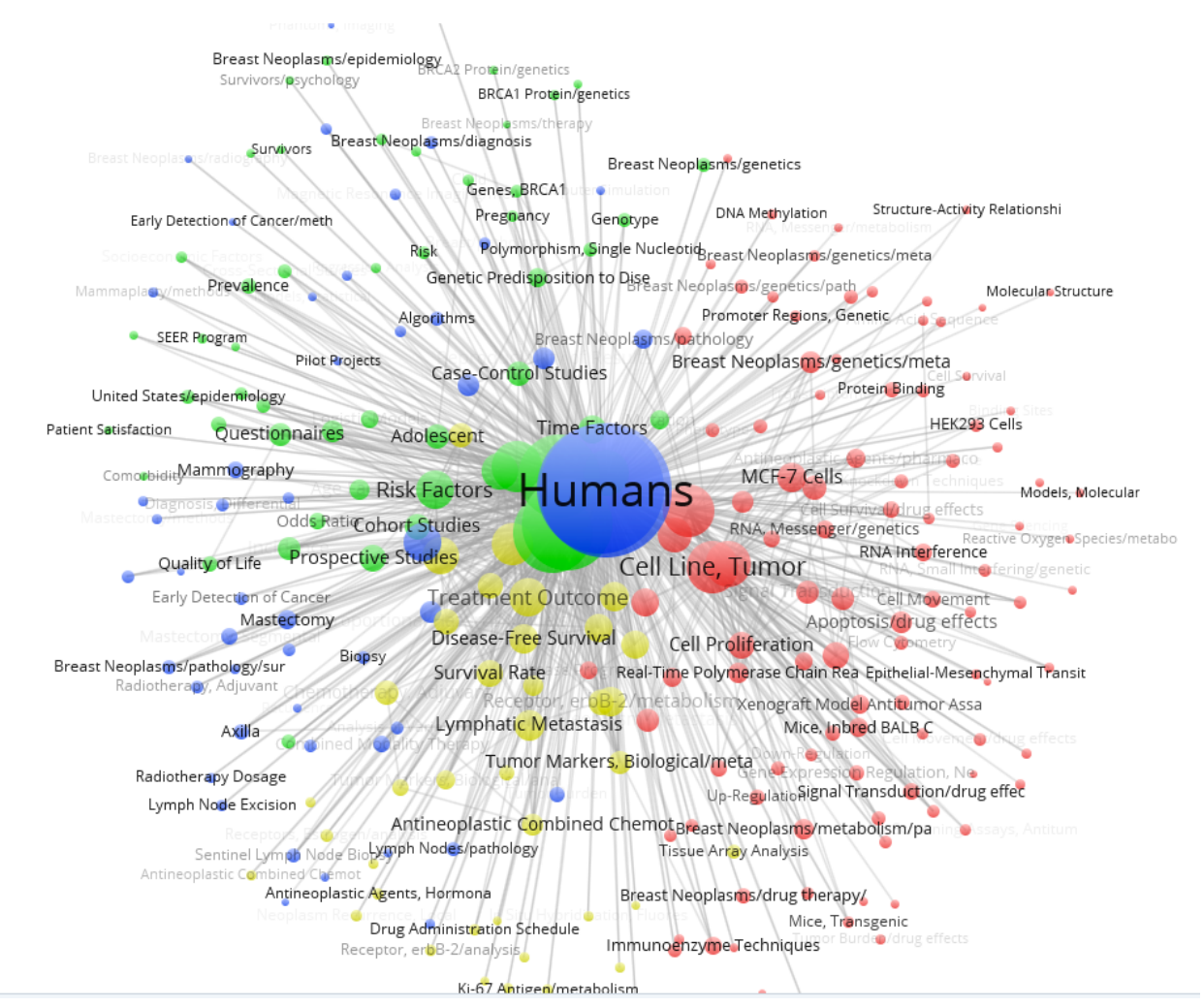

Figure 9. Co-occurrence in MESH for breast cancer research in 2013. Visualisation using VOSViewer software. Nodes: 244; links: 16344. Source: own source from cleaned PubMed data

The evolution of agency-funded MESH is presented in Tables 5 to 8. In ovarian cancer research, the two most important MESH in 2003 were still the most important terms in 2013. However, the increasing importance of cell line and genetics is clear in 2013 (Table 6).

The calculation of degree centrality in the affiliation matrix for MESH showed that those ranked highest in 2003 were "female", "humans", "animals", "tumour cells, cultured", "male" and "middle-aged". In 2013 , the highest centrality was for the terms "human", females", "animals", "middle-aged" and "cell line, tumour". Therefore, the study of cell lines acquired greater significance during the decade. In all cases, centrality was related to terms for which there was a higher coincidence in agencies funding them, because the matrices used to obtain affiliation matrices were 2-mode networks. The degree in the affiliation matrix for funding agencies indicates the agencies coinciding in the MESH they funded. In ovarian cancer research, these agencies were NCI, NCIHD, NCRR, and NIGMS in 2003, whilst in 2013, the agencies with the highest degree centrality were NCI, the Canadian Institutes of Health Research, the NICHS, Cancer Research UK, NIGMS and NCRR. Therefore, the most important agencies funding research in this field also funded other similar medical subject headings. This concurrence may explain the fact that these agencies appear together in co-funding cliques.

For breast research (Tables 7 and 8), the evolution in the MESH financed by agencies shows that "humans" and "female" were also the terms which appeared most frequently in papers. In this case, the increasing importance of terms related to cell line and genetics also became patent. 
When centrality measures were obtained, the terms with the highest degree centrality in 2003 were "humans", "female", "adult", "middle-aged" and "aged". In 2013, the terms with the highest degree were "humans", "female", "middle-aged", "adult", "cell line, tumour" and "aged". As is the case of ovarian research, the prevalence of the term "cell line" grew in importance. Moreover, the degree centrality in agencies indicated which ones coincided in funding research in these areas. In 2003, agencies like the NCI, NIDDK, NHLBI, NIGMS, NCRR, and NIEHS coincided in the medical subject headings they funded. In 2013, concurrence occurred in the agencies NCI, NCRR, NIGMS, Canadian Institutes of Health Research, PHS and Cancer Research UK. These agencies also appeared together in the previously calculated cliques.

On the other hand, when comparing centrality measures in MESH-by-MESH networks represented in Figures 6 to 9 whose results appear in Tables 5 to 8 , we can conclude that the most important terms in word co-occurrence were also those where agencies coincided most in funding.

Finally, we used VantagePoint software to obtain the MESH that were used in funded research papers in 2012 and those which started to be used in 2013. In the case of ovarian cancer, we found that terms like "cell division", "neoplasm proteins/genetics", "BRCA2 protein", "tumour suppressor proteins", "BRCA1 protein" and "receptor, erbB-2/immunology" were not included after 2012. For breast cancer, we detected this situation in terms like "tumour cell, cultured/drug effects", BRCA2 Protein", "Proto-Oncogen Proteins c-akt", "Cell cycle proteins", "aromatase proteins" and "carcinogens". Headings first used in 2013 in ovarian cancer showed "adenocarcinoma, clear cell/ pathology", "adenocarcinoma, mucinous/ pathology", "cytodiagnosis", "intestinal obstruction/ etiology/ surgery", "laparoscopy/ adverse effects", "ovarian neoplasms/ epidemiology/ pathology/ surgery", "ovarian neoplasms/ pathology/ radiography/ surgery", and "splenectomy". In breast cancer, new MESH in year 2013 were, for example, "bone density conservation agents/ adverse effects", "breast neoplasms, male/ diagnosis", "breast neoplasms/ classification/ pathology/ surgery", "genital neoplasms, female", "mastectomy, subcutaneous/ methods", "mastectomy/ mortality", "muscle, skeletal/ transplantation", and "neoplasm metastasis/ radiotherapy".

Table 5. Ranking of MESH funded by agencies in 2003 for ovarian cancer.

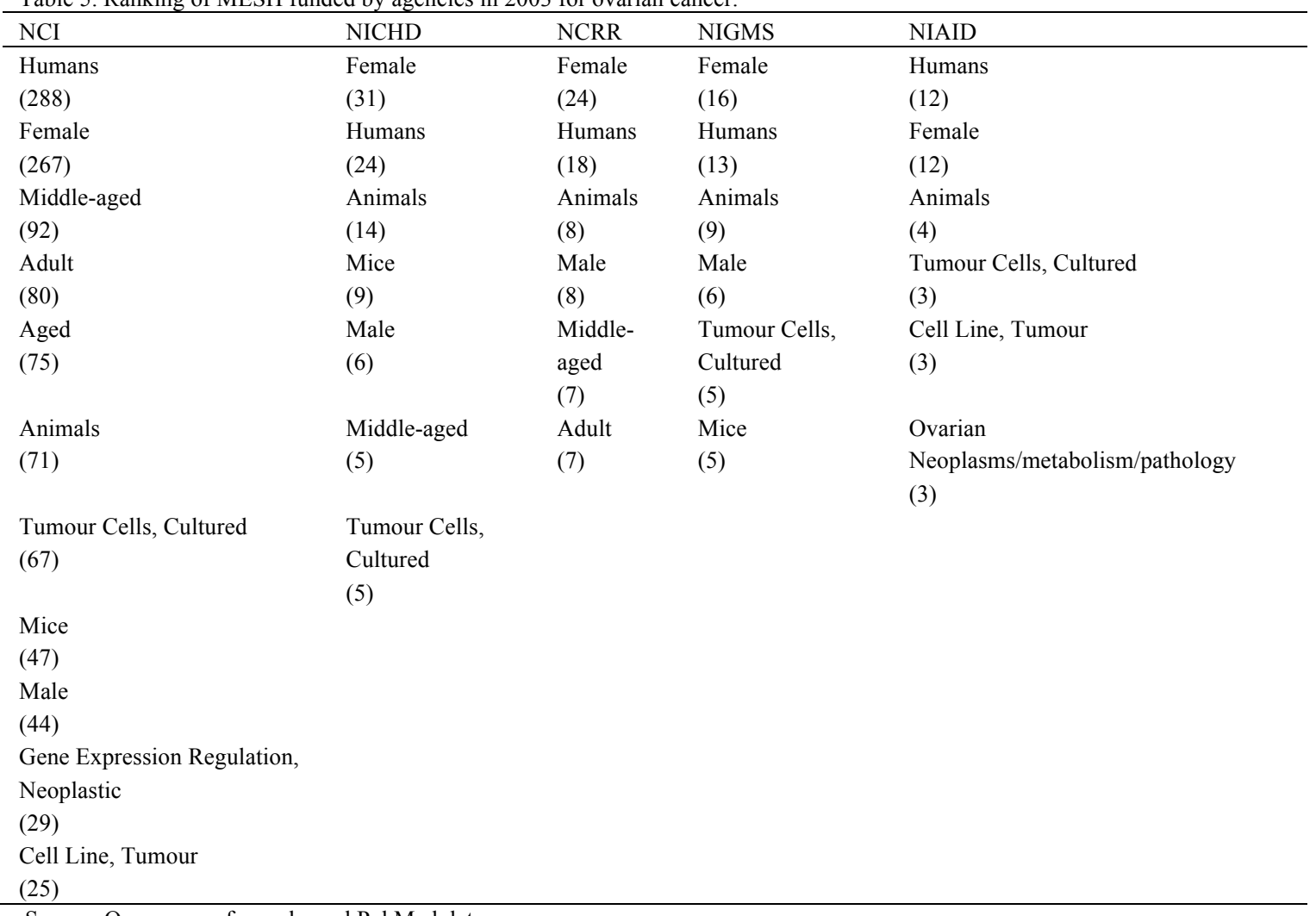

Source: Own source from cleaned PubMed data. 
Table 6. Ranking of MESH funded by agencies in 2013 for ovarian cancer.

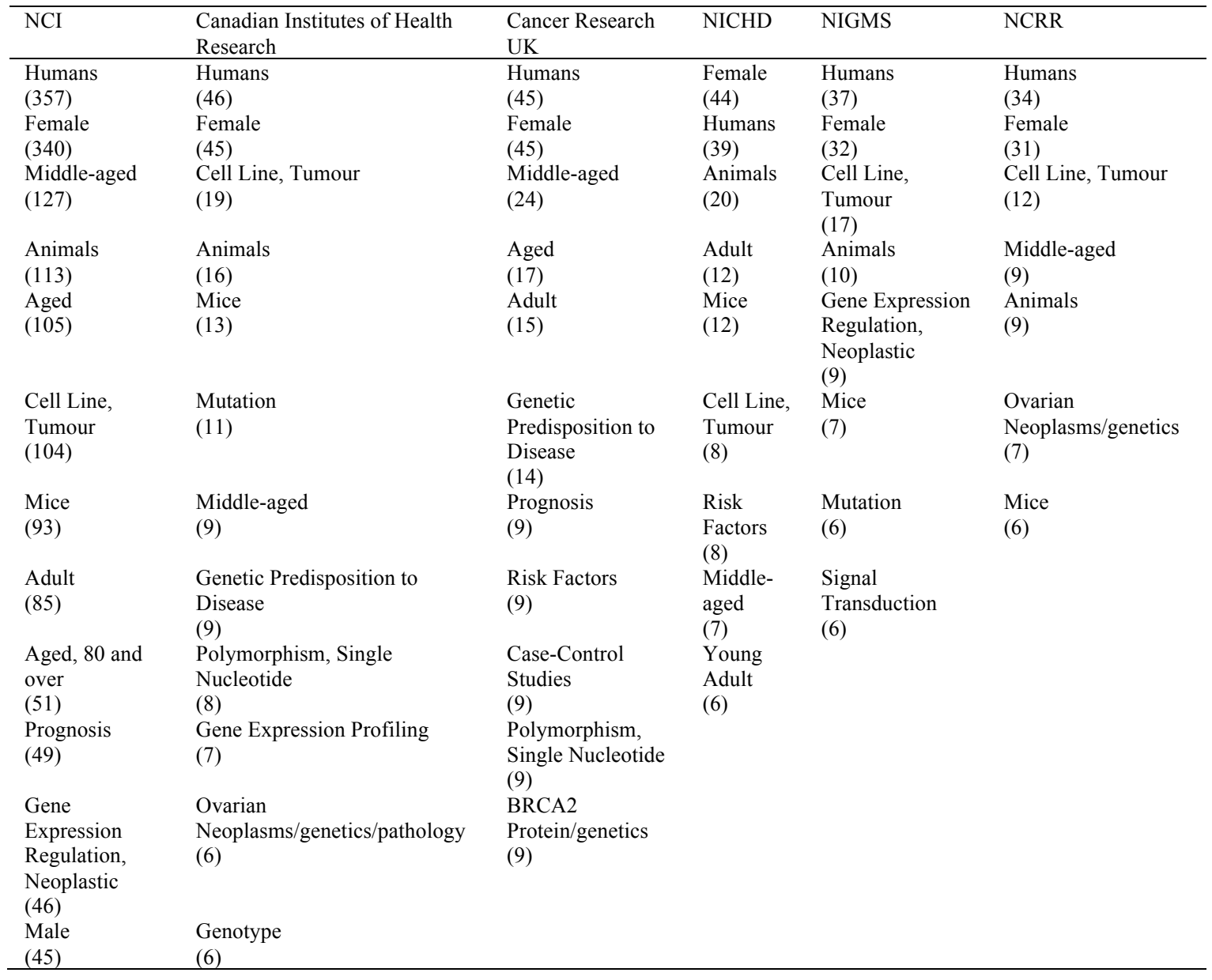

Source: Own source from cleaned PubMed data.

Table 7. Ranking of MESH funded by agencies in 2003 for breast cancer.

\begin{tabular}{|c|c|c|c|c|c|}
\hline $\mathrm{NCI}$ & NIDDK & NCRR & NIEHS & NIGMS & NICHD \\
\hline $\begin{array}{l}\text { Humans } \\
\text { (1114) }\end{array}$ & $\begin{array}{l}\text { Humans } \\
\text { (68) }\end{array}$ & $\begin{array}{l}\text { Humans } \\
(55)\end{array}$ & $\begin{array}{l}\text { Humans } \\
(55)\end{array}$ & $\begin{array}{l}\text { Humans } \\
\text { (55) }\end{array}$ & $\begin{array}{c}\text { Humans } \\
\text { (42) }\end{array}$ \\
\hline $\begin{array}{l}\text { Female } \\
(823)\end{array}$ & $\begin{array}{c}\text { Female } \\
(39)\end{array}$ & $\begin{array}{l}\text { Female } \\
\qquad(50)\end{array}$ & $\begin{array}{c}\text { Female } \\
(32)\end{array}$ & $\begin{array}{c}\text { Female } \\
\text { (34) }\end{array}$ & $\begin{array}{c}\text { Female } \\
(38)\end{array}$ \\
\hline $\begin{array}{l}\text { Middle-aged } \\
\text { (353) }\end{array}$ & $\begin{array}{l}\text { Animals } \\
\text { (32) }\end{array}$ & $\begin{array}{l}\text { Animals } \\
\text { (21) }\end{array}$ & $\begin{array}{l}\text { Animals } \\
(21)\end{array}$ & $\begin{array}{c}\text { Animals } \\
\text { (28) }\end{array}$ & $\begin{array}{c}\text { Animals } \\
\text { (17) }\end{array}$ \\
\hline $\begin{array}{l}\text { Animals } \\
\text { (313) }\end{array}$ & $\begin{array}{l}\text { Tumour Cells, } \\
\text { Cultured } \\
\text { (24) }\end{array}$ & $\begin{array}{l}\text { Middle-aged } \\
\text { (18) }\end{array}$ & $\begin{array}{l}\text { Tumour Cells, } \\
\text { Cultured } \\
(21)\end{array}$ & $\begin{array}{c}\text { Tumour } \\
\text { Cells, } \\
\text { Cultured } \\
\text { (16) }\end{array}$ & $\begin{array}{l}\text { Adult } \\
(12)\end{array}$ \\
\hline $\begin{array}{l}\text { Adult } \\
(302)\end{array}$ & $\begin{array}{l}\text { Mice } \\
(19)\end{array}$ & $\begin{array}{l}\text { Adult } \\
(16)\end{array}$ & $\begin{array}{c}\text { Mice } \\
(13)\end{array}$ & $\begin{array}{c}\text { Mice } \\
(15)\end{array}$ & $\begin{array}{c}\text { Tumour } \\
\text { Cells, } \\
\text { Cultured } \\
\text { (10) }\end{array}$ \\
\hline $\begin{array}{l}\text { Aged } \\
(265)\end{array}$ & $\begin{array}{c}\text { Transfection } \\
\text { (14) }\end{array}$ & $\begin{array}{l}\text { Aged } \\
(13)\end{array}$ & & & $\begin{array}{l}\text { Mice } \\
(10)\end{array}$ \\
\hline $\begin{array}{l}\text { Tumour } \\
\text { Cells, } \\
\text { Cultured } \\
\text { (223) }\end{array}$ & $\begin{array}{c}\text { Male } \\
(13)\end{array}$ & $\begin{array}{c}\text { Tumour Cells, } \\
\text { Cultured } \\
\text { (13) }\end{array}$ & & & \\
\hline $\begin{array}{l}\text { Mice } \\
(220)\end{array}$ & $\begin{array}{c}\text { Molecular Sequence } \\
\text { Data }\end{array}$ & $\begin{array}{l}\text { Mice } \\
(11)\end{array}$ & & & \\
\hline
\end{tabular}


(10)

$\begin{array}{lr}\text { Male } & \text { Male } \\ (146) & (10) \\ \text { Cell Line, } & \\ \text { Tumour } & \\ (126) & \\ \text { Risk Factors } & \\ (125) & \\ \text { Case-Control } & \\ \text { Studies } & \\ \text { (102) } & \\ \text { Time Factors } & \\ (100) & \end{array}$

Source: Own source from cleaned PubMed data

Table 8. Ranking of MESH funded by agencies in 2013 for breast cancer.

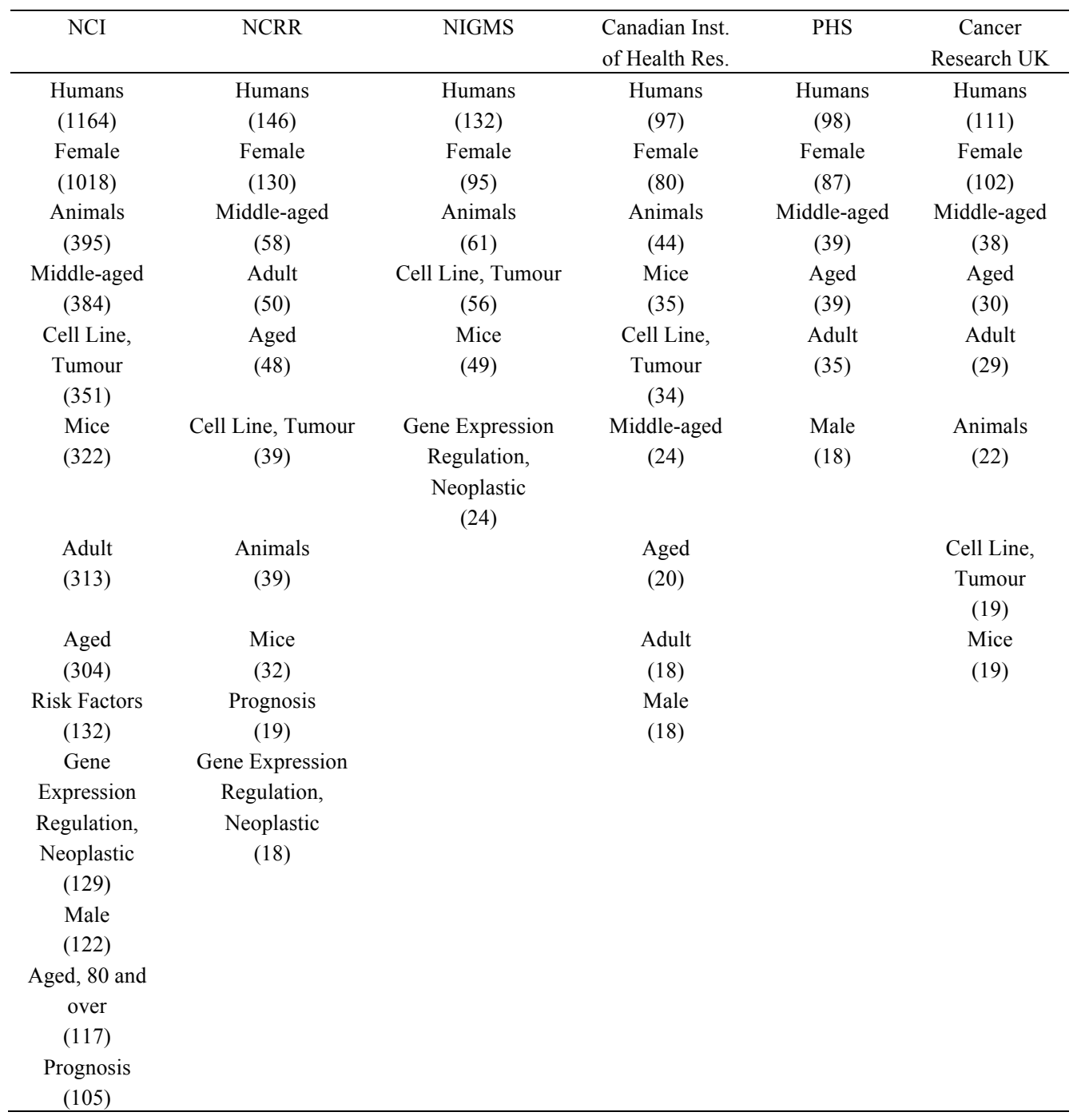

Source: Own source from cleaned PubMed data 


\section{Conclusions}

In this paper, we have analysed the patterns of co-funded research in two medical topics and demonstrated how this pattern varies depending on cross-agencies and cross-national collaboration in funding. Moreover, we have studied the relationship between funding agencies and the medical subject headings they set out to fund. The paper contributes, in an empirical and exploratory manner, to a growing body of knowledge concerning the production of knowledge, and how this knowledge is produced and affected by the choices and instruments of funding agencies.

Furthermore, co-funding research analysis gives researchers a thorough insight into the most important institutions that support research in a particular topic, and shows the mediator agencies to be contacted when it is difficult to achieve a direct link with a funding star --which in our analysis is the NCI. Moreover, we can also observe which countries are most directly linked to the United States, and which are better positioned, depending on the topic. For example, if we were trying to look for a mediator in ovarian cancer, we would find more opportunities in United Kingdom; if the topic were breast cancer, we would find our mediator in Canada.

In this paper, we have also detected a trend in agencies to coincide with the MESH they fund. Nonetheless, it is difficult to determine whether they fund these headings because of their importance, or if they become important because agencies fund them. This is an important area for further research. Furthermore, it is readily apparent that agencies, by and large, do not work together.

Analysing a medical bibliography involves difficulties, as we have encountered in our data processing. For example, although the PubMed database allowed us to download all the data quickly, cleaning the acknowledgement data took a long time. As the data included the project, the funding agencies, as well as other information, we had to delete the unnecessary data on a project-by-project basis. Another important difficulty was related to limits in working with a large amount of data with VantagePoint and Windows; fortunately we were able to solve this.

\section{Acknowledgments}

We would like to thank the reviewers for a previous draft presented to the Global TechMining Conference 2014. Their ideas have enabled us to improve the results and conclusions.

\section{References}

1. Andersen, J.P., Bøgsted, M., Dybkær, K., Mellqvist, U.H., Morgan, G.J., Goldschmidt, H., Dimopoulos, M.A., Einsele, H., San Miguel, J., Palumbo, A., Sonneveld, P., and Hans Erik Johnsen, H.E. (2015) Global Myeloma Research Clusters, Output, and Citations: A Bibliometric Mapping and Clustering Analysis. PLoS ONE, 10.1.

2. Barreto Lang, P., Castro Gouveia, F. and Leta, J. (2013) Cooperation in Health: Mapping Collaborative Networks on the Web. PLOS ONE, 8.8.

3. Bastian, M., Heymann S. and Jacomy M. (2009) Gephi: an open source software for exploring and manipulating networks. International AAAI Conference on Weblogs and Social Media, North America, mar. 2009. Available at: <http://www.aaai.org/ocs/index.php/ICWSM/09/paper/view/154/1009>. Date accessed: 21 Feb. 2015.

4. Borgatti, S.P., Everett, M.G. and Johnson, J.C. (2013) Analyzing Social Networks. SAGE Publications. London, U.K.

5. Bozeman, B. (2000) Technology transfer and public policy: A review of research. Research Policy, 29.4-5: 627655.

6. Brickman, R. and Rip, A. (1979) Science policy advisory councils in France, the Netherlands, and the United States, 1957-1977: A comparative analysis. Social Studies of Science, 9.2: 167-198.

7. Catalá-López, F., Alonso-Arroyo, A., Hutton, B., Aleixandre-Benavent, R. and Moher, D. (2014) Global collaborative networks on meta-analyses of randomized trials published in high impact factor medical journals: a social network analysis. BMC Medicine, 12.15: 1-17. 
8. Cobo, M.J., López-Herrera, A.G., Herrera-Viedma, E. and Herrera, F. (2011) Science Mapping Software Tools: Review, Analysis, and Cooperative Study Among Tools. Journal of The American Society For Information Science and Technology, 62.7:1382-1402.

9. Cowan, R. (1991) Tortoises and hares: Choice among technologies of unknown merit. The Economic Journal, 101.407: 801-814.

10. Cunningham, S.W. (2009) A comparative political theory of national science provision. Atlanta Conference on Science and Technology Policy, Atlanta, GA.

11. Cunningham, S.W. and Werker, C. (2012) Proximity and collaboration in European nanotechnology. Papers in Regional Science, 91.4: 723-742.

12. Dasgupta, P. and David, P. A. (1994) Toward a new economics of science. Research Policy, 23.5: 487-521.

13. de Nooy, W., Mrvar, A. and Batagelj, V. (2012) Exploratory Social Network Analysis with Pajek. Cambridge Universtity Press.

14. Doel, R.E. (2003) Constituting the postwar earth sciences: The military's influence on the environmental sciences in the USA after 1945. Social Studies of Science, 33.5: 635-666.

15. Feng, F., Zhang, L., Du, Y. and Wang, W. (2015) Visualization and quantitative study in bibliographic databases: A case in the field of university-industry cooperation. Journal of Informetrics, 9: 118-134.

16. Hanneman, R.A. and Riddle, M. (2011) Concepts and measures for basic network analysis. The Sage handbook of social network analysis, 340-369.

17. Kim, H.D, Lee, D.H., Choe, H. and Seo, I.W. (2014). The evolution of cluster network structure and firm growth: a study of industrial software clusters. Scientometrics, 99: 77-95.

18. Kolaczyk, E.D. (2009) Statistical Analysis of Network Data. Springer New York.

19. Kumar, S. and Jan, J.M. (2013) Mapping research collaborations in the business and management field in Malaysia, 1980-2010. Scientometrics, 97: 491-517.

20. Lassman, T.C. (2005) Government science in postwar America: Henry A. Wallace, Edward U. Condon, and the transformation of the National Bureau of Standards, 1945-1951. ISIS, 96.1: 25-51.

21. Lewison, G. (1998) Gastroenterology research in the United Kingdom: Funding sources and impact. GUT, 43.2: 288-293.

22. Leydesdorff, L. and Zaal, R. (1988) Co-words and citations relations between document sets and environments. Informetrics, 87/88: 105-119.

23. Light, R.P., Polley, D.E. and Börner, K. (2014) Open data and open code for big science of science studies. Scientometrics, 101: 1535-1551.

24. Narin, F., Hamilton, K.S. and Olivastro, D. (1997) The increasing linkage between U.S. technology and public science. Research Policy, 26.3: 317-330.

25. Neff, M.W. and Corley, E.A. (2009) 35 years and 160,000 articles: A bibliometric exploration of the evolution of ecology. Scientometrics, 80.3: 6579-6824.

26. Negro, S.O., Alkemade, F. and Hekkert, M.P. (2012) Why does renewable energy diffuse so slowly: A review of innovation system problems? Renewable and Sustainable Energy Reviews, 16.6: 3836-3846.

27. Nowotny, H., Scott, P. and Gibbons, M. (2003) Mode 2' revisited: The new production of knowledge. Minerva, 41: 179-194.

28. Ozcan, S. and Islam, N. (2013) Collaborative networks and technology clusters - The case of nanowire. Technological Forecasting \& Social Change, 82: 155-131.

29. Porter, A. and Cunningham, S.W. (2005). Tech Mining. Exploiting New Technologies for Competitive Advantage. John Wiley \& Sons. New Jersey.

30. Qiu, J.P., Dong, K. and Yu, H.Q. (2014) Comparative study on structure and correlation among author cooccurrence networks in bibliometrics. Scientometrics, 101.2: 1345-1360.

31. Ramlogan, R. and Consoli, D. (2014) Dynamics of collaborative research medicine: the case of glaucoma. $J$ Technol Transf, 39: 544-566.

32. Ravikumar, S., Agrahari, A. and Singh. S.N. (2015) Mapping the intellectual structure of scientometrics: a coword analysis of the journal Scientometrics (2005-2010). Scientometrics, 102.1: 929-955.

33. Siqueiros-García, J.M., Hernández-Lemus, E., García-Herrera, R. and Robina-Galatas, A. (2014) Mapping the Structure and Dynamics of Genomics- Related MeSH Terms Complex Networks. PLoS ONE, 9.4.

34. Stirling, A. (2007) A general framework for analysing diversity in science. Journal of the Royal Society Interface, 4.15: 707-719.

35. Suominen, A. (2014). Phases of growth in a green tech research network: a bibliometric evaluation of fuel cell technology from 1991 to 2010. Scientometrics, 100.1: 51-72.

36. Sutherland, W.J., Bellingan L., Bellingham J.R., Blackstock J.J., Bloomfield R.M., Bravo M., Cadman V.M., Cleevely D.D., Clements A., Cohen A.S., Cope D.R., Daemmrich A.A., Devecchi C., Anadon L.D., Denegri S., Doubleday R., Dusic N.R., Evans R.J., Feng W.Y., Godfray H.C.J., Harris P., Hartley S.E., Hester A.J., Holmes J., Hughes A., Hulme M., Irwin C., Jennings R.C., Kass G.S., Littlejohns P., Marteau T.M., McKee G., Millstone E.P., Nuttall W.J., Owens S., Parker M.M., Pearson S., Petts J., Ploszek R., Pullin A.S., Reid G., Richards K.S., Robinson J.G., Shaxson L., Sierra L., Smith B.G., Spiegelhalter D.J., Stilgoe J., Stirling A., Tyler C.P., Winickoff D.E. and Zimmern R.L. (2012). A Collaboratively-Derived Science-Policy Research Agenda. Plos One, 7.3. 
37. Swar, B. and Khan, G.F. (2014). Mapping ICT knowledge infrastructure in South Asia. Scientometrics, 99: 117137.

38. Tahmooresnejad, L., Beaudry, C., and Schiffauerova, A. (2014) The role of public funding in nanotechnology scientific production: Where Canada stands in comparison to the United States. Scientometrics, 102.1: 753-787.

39. van Eck, N.J. and Waltman, L. (2010) Software survey: VOSviewer, a computer program for bibliometric mapping. Scientometrics, 84: 523-538.

40. Vanderelst, D. and Speybroeck, N. (2013) Scientometrics reveals funding priorities in medical research policy. Journal of Informetrics, 7: 240-247.

41. Weinberg, A. (1962) Criteria for scientific choice. Minerva, 1.2: 158-171.

42. Yu, C., Davis, C. and Dijkema, G.P.J. (2013) Understanding the Evolution of Industrial Symbiosis Research A Bibliometric and Network Analysis (1997-2012). Journal of Industrial Ecology, 18.2: 280-293.

43. Zhang, C., Yu, Q., Fan, Q. and Duan, Z. (2013) Research collaboration in health management research communities. BMC Medical Informatics and Decision Making, 13.52: 1-13.

44. Zhang. J., Xie, J., Hou, W., Tu, X., Xu, J., Song, F., Wang, Z., and Lu, Z. (2012) Mapping the Knowledge Structure of Research on Patient Adherence: Knowledge Domain Visualization Based Co-Word Analysis and Social Network Analysis. PLoS ONE, 7.4.

45. Zhou, P. and Tian, H. (2014) Funded collaboration research in mathematics in China. Scientometrics, 99: 695715

\section{Annex 1. Cliques in 2013 for ovarian cancer}

1. NCI NIH HHS/United States; Canadian Institutes of Health Research/Canada; NICHD NIH HHS/United States; NIGMS NIH HHS/United States; NCRR NIH HHS/United States; PHS HHS/United States; NIEHS NIH HHS/United States.

2. NCI NIH HHS/United States; NICHD NIH HHS/United States; NIGMS NIH HHS/United States; NCRR NIH HHS/United States; NCATS NIH HHS/United States; NHLBI NIH HHS/United States.

3. NCI NIH HHS/United States; NICHD NIH HHS/United States; NIGMS NIH HHS/United States; NCRR NIH HHS/United States; NIH HHS/United States.

4. NCI NIH HHS/United States; Canadian Institutes of Health Research/Canada; Cancer Research UK/United Kingdom; NIGMS NIH HHS/United States; NCRR NIH HHS/United States; Medical Research Council/United Kingdom; PHS HHS/United States; Wellcome Trust/United Kingdom.

5. NCI NIH HHS/United States; Canadian Institutes of Health Research/Canada; Cancer Research UK/United Kingdom; NIGMS NIH HHS/United States; NCRR NIH HHS/United States; PHS HHS/United States; NIEHS NIH HHS/United States.

6. NCI NIH HHS/United States; NIGMS NIH HHS/United States; NCRR NIH HHS/United States; NHLBI NIH HHS/United States; NIAID NIH HHS/United States.

7. NCI NIH HHS/United States; NIGMS NIH HHS/United States; NCRR NIH HHS/United States; NHLBI NIH HHS/United States; NHGRI NIH HHS/United States.

8. NCI NIH HHS/United States; NIGMS NIH HHS/United States; NCRR NIH HHS/United States; NHLBI NIH HHS/United States; NLM NIH HHS/United States.

9. NCI NIH HHS/United States; NIGMS NIH HHS/United States; NCATS NIH HHS/United States; NHLBI NIH HHS/United States; NIDDK NIH HHS/United States.

10. NCI NIH HHS/United States; Cancer Research UK/United Kingdom; NIGMS NIH HHS/United States; NIDDK NIH HHS/United States.

11. NCI NIH HHS/United States; NIGMS NIH HHS/United States; NHLBI NIH HHS/United States; Howard Hughes Medical Institute/United States.

12. NCI NIH HHS/United States; NIGMS NIH HHS/United States; NIMHD NIH HHS/United States.

13. NCI NIH HHS/United States; Cancer Research UK/United Kingdom; Medical Research Council/United Kingdom; Department of Health/United Kingdom; Arthritis Research UK/United Kingdom.

14. NCI NIH HHS/United States; NCRR NIH HHS/United States; NHLBI NIH HHS/United States; NIAID NIH HHS/United States; NIBIB NIH HHS/United States.

15. NCI NIH HHS/United States; NICHD NIH HHS/United States; NCRR NIH HHS/United States; NHLBI NIH HHS/United States; NIBIB NIH HHS/United States.

16. NCI NIH HHS/United States; NICHD NIH HHS/United States; NCRR NIH HHS/United States; NIBIB NIH HHS/United States; NIH HHS/United States.

17. NCI NIH HHS/United States; NHLBI NIH HHS/United States; NIBIB NIH HHS/United States; Howard Hughes Medical Institute/United States.

18. NCI NIH HHS/United States; NIBIB NIH HHS/United States; Howard Hughes Medical Institute/United States; NCCDPHP CDC HHS/United States.

19. NCI NIH HHS/United States; NICHD NIH HHS/United States; NIBIB NIH HHS/United States; NIDCR NIH HHS/United States; NIH HHS/United States.

20. NCI NIH HHS/United States; NICHD NIH HHS/United States; NIEHS NIH HHS/United States; NIA NIH HHS/United States.

21. NCI NIH HHS/United States; NICHD NIH HHS/United States; NCATS NIH HHS/United States; NIA NIH HHS/United States.

22. NCI NIH HHS/United States; NICHD NIH HHS/United States; NIA NIH HHS/United States; NIMH NIH HHS/United States.

23. NCI NIH HHS/United States; NCATS NIH HHS/United States; NIDDK NIH HHS/United States; NIA NIH HHS/United States. 
24. NCI NIH HHS/United States; NCATS NIH HHS/United States; NIDDK NIH HHS/United States; NIAMS NIH HHS/United States.

25. NCI NIH HHS/United States; NCRR NIH HHS/United States; NCATS NIH HHS/United States; NIAMS NIH HHS/United States.

26. NCI NIH HHS/United States; NCRR NIH HHS/United States; NIAID NIH HHS/United States; NIAMS NIH HHS/United States.

27. NCI NIH HHS/United States; NINDS NIH HHS/United States; NIMH NIH HHS/United States.

28. NCI NIH HHS/United States; Cancer Research UK/United Kingdom; Medical Research Council/United Kingdom; Wellcome Trust/United Kingdom; Chief Scientist Office/United Kingdom.

29. NCI NIH HHS/United States; NIEHS NIH HHS/United States; NIDA NIH HHS/United States.

30. NCI NIH HHS/United States; NICHD NIH HHS/United States; NCATS NIH HHS/United States; NIDCR NIH HHS/United States.

31. NCI NIH HHS/United States; Wellcome Trust/United Kingdom; NIDCR NIH HHS/United States; WETP NIH HHS/United States.

32. NCI NIH HHS/United States; NHGRI NIH HHS/United States; NIMH NIH HHS/United States.

33. NCI NIH HHS/United States; Cancer Research UK/United Kingdom; Medical Research Council/United Kingdom; Wellcome Trust/United Kingdom; Arthritis Research UK/United Kingdom.

34. NCI NIH HHS/United States; NHLBI NIH HHS/United States; NHGRI NIH HHS/United States; WHI NIH HHS/United States.

35. NCI NIH HHS/United States; Cancer Research UK/United Kingdom; NCRR NIH HHS/United States; NIEHS NIH HHS/United States; CCR NIH HHS/United States.

36. Canadian Institutes of Health Research/Canada; NICHD NIH HHS/United States; NIGMS NIH HHS/United States; NCRR NIH HHS/United States; NIEHS NIH HHS/United States; British Heart Foundation/United Kingdom.

37. Canadian Institutes of Health Research/Canada; NIGMS NIH HHS/United States; NCRR NIH HHS/United States; Wellcome Trust/United Kingdom; British Heart Foundation/United Kingdom.

38. NICHD NIH HHS/United States; NIA NIH HHS/United States; NINR NIH HHS/United States.

\section{Annex 2. Cliques in 2013 for breast cancer}

1. NCI NIH HHS/United States; NCRR NIH HHS/United States; NIGMS NIH HHS/United States; PHS HHS/United States NIDDK NIH HHS/United States; NHLBI NIH HHS/United States; NCATS NIH HHS/United States; NIA NIH HHS/United States; NICHD NIH HHS/United States; NIMHD NIH HHS/United States.

2. NCI NIH HHS/United States; NCRR NIH HHS/United States; NIGMS NIH HHS/United States; PHS HHS/United States; NIDDK NIH HHS/United States; NHLBI NIH HHS/United States; NCATS NIH HHS/United States; NIA NIH HHS/United States; NICHD NIH HHS/United States; NIDCR NIH HHS/United States.

3. NCI NIH HHS/United States; NCRR NIH HHS/United States; NIGMS NIH HHS/United States; PHS HHS/United States; NIDDK NIH HHS/United States; NHLBI NIH HHS/United States; NIEHS NIH HHS/United States; NCATS NIH HHS/United States; NIBIB NIH HHS/United States; NICHD NIH HHS/United States.

4. NCI NIH HHS/United States; NCRR NIH HHS/United States; NIGMS NIH HHS/United States; PHS HHS/United States; NIDDK NIH HHS/United States; NHLBI NIH HHS/United States; NIEHS NIH HHS/United States; NICHD NIH HHS/United States; NHGRI NIH HHS/United States.

5. NCI NIH HHS/United States; NCRR NIH HHS/United States; NIGMS NIH HHS/United States; PHS HHS/United States; NIDDK NIH HHS/United States; NHLBI NIH HHS/United States; NIEHS NIH HHS/United States; NIBIB NIH HHS/United States; NICHD NIH HHS/United States; NINDS NIH HHS/United States.

6. NCI NIH HHS/United States; NCRR NIH HHS/United States; NIGMS NIH HHS/United States; PHS HHS/United States; NIDDK NIH HHS/United States; NHLBI NIH HHS/United States; NIA NIH HHS/United States; NICHD NIH HHS/United States; NIDCR NIH HHS/United States; NINDS NIH HHS/United States.

7. NCI NIH HHS/United States; NCRR NIH HHS/United States; NIGMS NIH HHS/United States; PHS HHS/United States; NIDDK NIH HHS/United States; NHLBI NIH HHS/United States; NHGRI NIH HHS/United States; NIAID NIH HHS/United States; Howard Hughes Medical Institute/United States.

8. NCI NIH HHS/United States; NCRR NIH HHS/United States; NIGMS NIH HHS/United States; PHS HHS/United States; NIDDK NIH HHS/United States; NHLBI NIH HHS/United States; NIA NIH HHS/United States; NIAID NIH HHS/United States.

9. NCI NIH HHS/United States; NCRR NIH HHS/United States; NIGMS NIH HHS/United States; PHS HHS/United States; NIDDK NIH HHS/United States; NHLBI NIH HHS/United States; NCATS NIH HHS/United States; NIBIB NIH HHS/United States; Howard Hughes Medical Institute/United States.

10. NCI NIH HHS/United States; NCRR NIH HHS/United States; NIGMS NIH HHS/United States; PHS HHS/United States; NIDDK NIH HHS/United States; NHLBI NIH HHS/United States; NIBIB NIH HHS/United States; NINDS NIH HHS/United States; Howard Hughes Medical Institute/United States.

11. NCI NIH HHS/United States; NCRR NIH HHS/United States; NIGMS NIH HHS/United States; Canadian Institutes of Health Research/Canada; PHS HHS/United States; NIDDK NIH HHS/United States; NIA NIH HHS/United States; NIAID NIH HHS/United States.

12. NCI NIH HHS/United States; NCRR NIH HHS/United States; NIGMS NIH HHS/United States; Canadian Institutes of Health Research/Canada; PHS HHS/United States; NIDDK NIH HHS/United States; NIA NIH HHS/United States; NIDCR NIH HHS/United States.

13. NCI NIH HHS/United States; NCRR NIH HHS/United States; NIGMS NIH HHS/United States; Canadian Institutes of Health Research/Canada; PHS HHS/United States; NIDDK NIH HHS/United States; NIA NIH HHS/United States; NCCAM NIH HHS/United States.

14. NCI NIH HHS/United States; NCRR NIH HHS/United States; NIGMS NIH HHS/United States; Canadian Institutes of Health Research/Canada; PHS HHS/United States; NIDDK NIH HHS/United States; NIEHS NIH HHS/United States; NHGRI NIH HHS/United States.

15. NCI NIH HHS/United States; NCRR NIH HHS/United States; NIGMS NIH HHS/United States; Canadian Institutes of Health Research/Canada; PHS HHS/United States; NIDDK NIH HHS/United States; NIEHS NIH HHS/United States; NCCAM NIH HHS/United States. 
16. NCI NIH HHS/United States; NCRR NIH HHS/United States; NIGMS NIH HHS/United States; Canadian Institutes of Health Research/Canada; PHS HHS/United States; NIDDK NIH HHS/United States; NHGRI NIH HHS/United States; NIAID NIH HHS/United States.

17. NCI NIH HHS/United States; NCRR NIH HHS/United States; PHS HHS/United States; NIDDK NIH HHS/United States; NHLBI NIH HHS/United States; NIBIB NIH HHS/United States; NINDS NIH HHS/United States; NIAMS NIH HHS/United States; Howard Hughes Medical Institute/United States.

18. NCI NIH HHS/United States; NCRR NIH HHS/United States; PHS HHS/United States; NIDDK NIH HHS/United States; NHLBI NIH HHS/United States; NIA NIH HHS/United States; NINDS NIH HHS/United States; NIAMS NIH HHS/United States.

19. NCI NIH HHS/United States; NCRR NIH HHS/United States; PHS HHS/United States; NIDDK NIH HHS/United States; NHLBI NIH HHS/United States; NIAMS NIH HHS/United States; AHRQ HHS/United States.

20. NCI NIH HHS/United States; NCRR NIH HHS/United States; PHS HHS/United States; NIDDK NIH HHS/United States; NHLBI NIH HHS/United States; NCATS NIH HHS/United States; NICHD NIH HHS/United States; NIMHD NIH HHS/United States; AHRQ HHS/United States.

21. NCI NIH HHS/United States; NCRR NIH HHS/United States; PHS HHS/United States; NIDDK NIH HHS/United States; NHLBI NIH HHS/United States; NICHD NIH HHS/United States; NHGRI NIH HHS/United States; AHRQ HHS/United States.

22. NCI NIH HHS/United States; NCRR NIH HHS/United States; NIGMS NIH HHS/United States; Canadian Institutes of Health Research/Canada; PHS HHS/United States; Cancer Research UK/United Kingdom; NIEHS NIH HHS/United States.

23. NCI NIH HHS/United States; NCRR NIH HHS/United States; NIGMS NIH HHS/United States; Canadian Institutes of Health Research/Canada; PHS HHS/United States; Cancer Research UK/United Kingdom; NIA NIH HHS/United States.

24. NCI NIH HHS/United States; NCRR NIH HHS/United States; NIGMS NIH HHS/United States; PHS HHS/United States; Cancer Research UK/United Kingdom; Howard Hughes Medical Institute/United States.

25. NCI NIH HHS/United States; NCRR NIH HHS/United States; PHS HHS/United States; Cancer Research UK/United Kingdom; NIEHS NIH HHS/United States; CCR NIH HHS/United States.

26. NCI NIH HHS/United States; NCRR NIH HHS/United States; PHS HHS/United States; NCATS NIH HHS/United States; NIA NIH HHS/United States; NICHD NIH HHS/United States; NINR NIH HHS/United States.

27. NCI NIH HHS/United States; NCRR NIH HHS/United States; NIGMS NIH HHS/United States; NHLBI NIH HHS/United States; NIEHS NIH HHS/United States; NIBIB NIH HHS/United States; NIH HHS/United States; NIDA NIH HHS/United States.

28. NCI NIH HHS/United States; NCRR NIH HHS/United States; NIGMS NIH HHS/United States; NHLBI NIH HHS/United States; NIEHS NIH HHS/United States; NHGRI NIH HHS/United States; NIH HHS/United States.

29. NCI NIH HHS/United States; NCRR NIH HHS/United States; NIGMS NIH HHS/United States; NHLBI NIH HHS/United States; NHGRI NIH HHS/United States; NIAID NIH HHS/United States; Howard Hughes Medical Institute/United States; NIH HHS/United States.

30. NCI NIH HHS/United States; NCRR NIH HHS/United States; NIGMS NIH HHS/United States; NHLBI NIH HHS/United States; NIAID NIH HHS/United States; NIH HHS/United States; NIDA NIH HHS/United States.

31. NCI NIH HHS/United States; NCRR NIH HHS/United States; NIGMS NIH HHS/United States; NHLBI NIH HHS/United States; NIBIB NIH HHS/United States; Howard Hughes Medical Institute/United States; NIH HHS/United States.

32. NCI NIH HHS/United States; NCRR NIH HHS/United States; NIGMS NIH HHS/United States; NIEHS NIH HHS/United States; NIH HHS/United States; NCCAM NIH HHS/United States.

33. NCI NIH HHS/United States; NCRR NIH HHS/United States; NIDDK NIH HHS/United States; NHLBI NIH HHS/United States; NIEHS NIH HHS/United States; NHGRI NIH HHS/United States; NIAAA NIH HHS/United States.

34. NCI NIH HHS/United States; NCRR NIH HHS/United States; NIGMS NIH HHS/United States; NHLBI NIH HHS/United States; NIEHS NIH HHS/United States; NIBIB NIH HHS/United States; NICHD NIH HHS/United States; NINDS NIH HHS/United States; NIDA NIH HHS/United States.

35. NCI NIH HHS/United States; NCRR NIH HHS/United States; NIGMS NIH HHS/United States; NHLBI NIH HHS/United States; NIA NIH HHS/United States; NICHD NIH HHS/United States; NINDS NIH HHS/United States; NIDA NIH HHS/United States.

36. NCI NIH HHS/United States; NCRR NIH HHS/United States; NIGMS NIH HHS/United States; NHLBI NIH HHS/United States; NIA NIH HHS/United States; NICHD NIH HHS/United States; NIMHD NIH HHS/United States; NIDA NIH HHS/United States.

37. NCI NIH HHS/United States; NCRR NIH HHS/United States; NIGMS NIH HHS/United States; NHLBI NIH HHS/United States; NIA NIH HHS/United States; NIAID NIH HHS/United States; NIDA NIH HHS/United States.

38. NCI NIH HHS/United States; NCRR NIH HHS/United States; NIGMS NIH HHS/United States; Canadian Institutes of Health Research/Canada; NIA NIH HHS/United States; NIAID NIH HHS/United States; NIDA NIH HHS/United States.

39. NCI NIH HHS/United States; NCRR NIH HHS/United States; NIGMS NIH HHS/United States; Canadian Institutes of Health Research/Canada; NIEHS NIH HHS/United States; NIDA NIH HHS/United States.

40. NCI NIH HHS/United States; NCRR NIH HHS/United States; NIEHS NIH HHS/United States; NIDA NIH HHS/United States; RMOD NIH HHS/United States.

41. NCI NIH HHS/United States; NCRR NIH HHS/United States; NIGMS NIH HHS/United States; NIAID NIH HHS/United States; FIC NIH HHS/United States.

42. NCI NIH HHS/United States; NCRR NIH HHS/United States; NIGMS NIH HHS/United States; NICHD NIH HHS/United States; FIC NIH HHS/United States.

43. NCI NIH HHS/United States; NCRR NIH HHS/United States; NIDDK NIH HHS/United States; NHLBI NIH HHS/United States; NCATS NIH HHS/United States; NIBIB NIH HHS/United States; NEI NIH HHS/United States.

44. NCI NIH HHS/United States; NIGMS NIH HHS/United States; Canadian Institutes of Health Research/Canada; PHS HHS/United States; Cancer Research UK/United Kingdom; NIA NIH HHS/United States; Medical Research Council/United Kingdom.

45. NCI NIH HHS/United States; NIGMS NIH HHS/United States; Canadian Institutes of Health Research/Canada; Cancer Research UK/United Kingdom; NIA NIH HHS/United States; Medical Research Council/United Kingdom; NIMH NIH HHS/United States.

46. NCI NIH HHS/United States; NIGMS NIH HHS/United States; PHS HHS/United States; Cancer Research UK/United Kingdom; Medical Research Council/United Kingdom; Department of Health/United Kingdom.

47. NCI NIH HHS/United States; NIGMS NIH HHS/United States; Cancer Research UK/United Kingdom; Medical Research Council/United Kingdom; NIMH NIH HHS/United States; Department of Health/United Kingdom. 
48. NCI NIH HHS/United States; Cancer Research UK/United Kingdom; Medical Research Council/United Kingdom; NIMH NIH HHS/United States; Department of Health/United Kingdom; British Heart Foundation/United Kingdom.

49. NCI NIH HHS/United States; Cancer Research UK/United Kingdom; Medical Research Council/United Kingdom; Department of Health/United Kingdom; Arthritis Research UK/United Kingdom.

50. NCI NIH HHS/United States; NIGMS NIH HHS/United States; NCATS NIH HHS/United States; NIA NIH HHS/United States; NICHD NIH HHS/United States; NIMH NIH HHS/United States; NIMHD NIH HHS/United States.

51. NCI NIH HHS/United States; NIGMS NIH HHS/United States; NIA NIH HHS/United States; NICHD NIH HHS/United States; NIMH NIH HHS/United States; NIMHD NIH HHS/United States; NIDA NIH HHS/United States.

52. NCI NIH HHS/United States; NIGMS NIH HHS/United States; NIA NIH HHS/United States; NICHD NIH HHS/United States; NIMH NIH HHS/United States; NINDS NIH HHS/United States; NIDA NIH HHS/United States.

53. NCI NIH HHS/United States; NIGMS NIH HHS/United States; Canadian Institutes of Health Research/Canada; NIA NIH HHS/United States; NIMH NIH HHS/United States; NIDA NIH HHS/United States.

54. NCI NIH HHS/United States; NIGMS NIH HHS/United States; NIBIB NIH HHS/United States; NICHD NIH HHS/United States; NIMH NIH HHS/United States; NINDS NIH HHS/United States; NIDA NIH HHS/United States.

55. NCI NIH HHS/United States; NIGMS NIH HHS/United States; NCATS NIH HHS/United States; NIBIB NIH HHS/United States; NICHD NIH HHS/United States; NIMH NIH HHS/United States.

56. NCI NIH HHS/United States; NIGMS NIH HHS/United States; NICHD NIH HHS/United States; NIMH NIH HHS/United States; NHGRI NIH HHS/United States.

57. NCI NIH HHS/United States; NIGMS NIH HHS/United States; Canadian Institutes of Health Research/Canada; NIMH NIH HHS/United States; NHGRI NIH HHS/United States.

58. NCI NIH HHS/United States; NIMH NIH HHS/United States; Austrian Science Fund FWF/Austria.

59. NCI NIH HHS/United States; PHS HHS/United States; NIDDK NIH HHS/United States; NHLBI NIH HHS/United States; NIA NIH HHS/United States; NICHD NIH HHS/United States; NCCDPHP CDC HHS/United States.

60. NCI NIH HHS/United States; PHS HHS/United States; NIA NIH HHS/United States; NICHD NIH HHS/United States; NCCDPHP CDC HHS/United States; NINR NIH HHS/United States.

61. NCI NIH HHS/United States; Canadian Institutes of Health Research/Canada; PHS HHS/United States; NIDDK NIH HHS/United States; NIA NIH HHS/United States; NCCDPHP CDC HHS/United States.

62. NCI NIH HHS/United States; PHS HHS/United States; NIDDK NIH HHS/United States; NHLBI NIH HHS/United States; NIEHS NIH HHS/United States; NICHD NIH HHS/United States; NCCDPHP CDC HHS/United States.

63. NCI NIH HHS/United States; Canadian Institutes of Health Research/Canada; PHS HHS/United States; NIDDK NIH HHS/United States; NIEHS NIH HHS/United States; NCCDPHP CDC HHS/United States.

64. NCI NIH HHS/United States; NCCDPHP CDC HHS/United States; ODCDC CDC HHS/United States.

65. NCI NIH HHS/United States; PHS HHS/United States; NHLBI NIH HHS/United States; NIEHS NIH HHS/United States; NICHD NIH HHS/United States; NHGRI NIH HHS/United States; WHI NIH HHS/United States.

66. NCI NIH HHS/United States; PHS HHS/United States; NHLBI NIH HHS/United States; NIAMS NIH HHS/United States; WHI NIH HHS/United States.

67. NCI NIH HHS/United States; PHS HHS/United States; FDA HHS/United States.

68. Cancer Research UK/United Kingdom; Medical Research Council/United Kingdom; NIMH NIH HHS/United States; Biotechnology and Biological Sciences Research Council/United Kingdom.

69. Cancer Research UK/United Kingdom; Medical Research Council/United Kingdom; Chief Scientist Office/United Kingdom.

70. NIMH NIH HHS/United States; Department of Health/United Kingdom; European Research Council/International. 